\title{
Impact of Risk Aversion on Price and Quality Decisions under Demand Uncertainty via the CARA Utility Function
}

\author{
Qinqin Li, Zhiying Liu, and Yi He \\ School of Management, University of Science and Technology of China, Hefei, Anhui 230026, China \\ Correspondence should be addressed to Zhiying Liu; liuzhiy@ustc.edu.cn
}

Received 30 March 2014; Revised 11 June 2014; Accepted 12 June 2014; Published 10 July 2014

Academic Editor: Vladislav Kravchenko

Copyright (C) 2014 Qinqin Li et al. This is an open access article distributed under the Creative Commons Attribution License, which permits unrestricted use, distribution, and reproduction in any medium, provided the original work is properly cited.

\begin{abstract}
This paper investigates optimal price and quality decisions of a manufacturer-retailer supply chain under demand uncertainty, in which players are both risk-averse decision makers. The manufacturer determines the wholesale price and quality of the product, and the retailer determines the retail price. By means of game theory, we employ the constant absolute risk aversion (CARA) function to analyze two different supply chain structures, that is, manufacturer Stackelberg model (MS) and retailer Stackelberg model (RS). We then analyze the results to explore the effects of risk aversion of the manufacturer and the retailer upon the equilibrium decisions. Our results imply that both the risk aversion of the manufacturer and the retailer play an important role in the price and quality decisions. We find that, in general, in MS and RS models, the optimal wholesale price and quality decrease with the risk aversion of the manufacturer but increase with the risk aversion of the retailer, while the retail price decreases with the risk aversion of the manufacturer as well as the retailer. We also examine the impact of quality cost coefficient on the optimal decisions. Finally, numerical examples are presented to illustrate the different degree of effects of players' risk aversion on equilibrium results and to compare results in different models considered.
\end{abstract}

\section{Introduction}

Over the last couple of decades, the business environment has evolved to be increasingly complex that is characterized by high uncertainty and rapid and frequent changes. Any disruption in one firm can rapidly result in a significant adversary impact on the entire chain [1]. The demand uncertainty brings risk to the firm and influences its performance. For example, in the past two years due to weak demand and ambitious overexpansion, the domestic sports product enterprises in China have suffered from excessive inventory and have closed thousands of outlets to cope with the risk. Their business performance showed a relatively large degree of decline; for example, Li Ning suffered a net loss of $\$ 318.78$ million for 2012 and its revenue declined 24.5 percent yearon-year to $\$ 1.09$ billion.

The traditional assumption of risk-neutrality seems to be largely invalid for contemporary supply chain management. When facing random demand, the supply chain members, who are subject to financial risk, will be more concerned with the risk associated with demand uncertainties. The risk attitude of the firm towards demand uncertainty may significantly affect the decisions of supply chain members, such as pricing, production, purchasing, and quality or service investment. For example, Li Ning gave more wholesale discounts to his distributors and the retailer sold products at a discount under demand uncertainty. A risk-averse firm, who makes expensive quality investment decisions, faces uncertain demand potential and may not build adequate quality improvement. Further, different decision makers may have different degrees of risk aversion. How to incorporate individual's risk aversion into an applicable and implementable decision framework is definitely important. Motivated by the real business practice, in this paper, we analyze the optimal decisions of risk-averse players via the constant absolute risk aversion (CARA) utility function.

The CARA utility function is frequently used in risk management literature to assess various risks surrounding firms; the function also can be used in a specific operation research problem to derive quantitative solutions under uncertainty 
[2]. The CARA utility function in operations management has been applied to a number of different situations [2-7], in which the CARA function is employed to describe riskaverse behaviors of decision makers. Using the approach of CARA, we can obtain players' optimal decisions and capture the impact of risk aversion behavior.

Quality is one of the key competitive factors; research on quality improvement has been explored in various management issues [8-12]. However, these studies have been largely limited to risk-neutral decision makers. The literature dealing with both pricing and quality investment for riskaversion players is sparse, with the exception of Xie et al. [13]. They investigated the impact of various supply chain strategies and risk-averse behaviors of the players on quality investment and price decision in a supplier-manufacturer supply chain with uncertain demand. They only illustrated the impact of the manufacturer's risk tolerance on players' equilibrium decisions. They assumed exogenous wholesale price and showed that the utility of the supplier becomes negative when the manufacturer becomes less risk-averse. As such, when the manufacturer is risk-neutral, the supplier will not participate in production, which, nevertheless, does not correspond to reality. The reason for the above problems is that the wholesale price remains unchanged even if the supplier improves quality.

Unlike Xie et al. [13], we consider that the wholesale price is endogenous as most literature [10, 11, 14-16] did. The upstream manufacturer (supplier) invests in quality improvement in order to increase the attractiveness and value of the product. Undoubtedly, producing a higher quality product incurs more costs to the manufacturer. Using the wholesale price as a decision variable provides the manufacturer with an additional tool, with which to recuperate the quality investment costs and to counteract the vagaries of demand uncertainty, in accordance with the standard tenets of microeconomic theory [17]. Therefore, we do not restrict the manufacturer's decision process to simply improving the quality at a fixed wholesale price. Instead, the manufacturer decides the wholesale price and quality investment that optimizes the expected profit. We develop two Stackelberg game-theoretic analyses for the modified model and intend to get better insights into the effects of risk aversion of players on the optimal price and quality decisions. The results we obtain from this analysis differ significantly from the original and some new interesting managerial implications are proposed.

In this paper, we derive the optimal price and quality decisions of a manufacturer-retailer supply chain under demand uncertainty, in which players are both risk-averse decision makers, and examine how risk aversion affects the equilibrium results. Our analytical results reveal the following findings. (i) In general, in manufacturer Stackelberg model (MS) and retailer Stackelberg model (RS), the optimal wholesale price and quality decrease with the risk aversion of the manufacturer but increase with the risk aversion of the retailer, while the retail price decreases with the risk aversion of the manufacturer as well as the retailer. (ii) The results indicate that the wholesale price, quality, and retail price all decrease with the quality cost coefficient. (iii) The two players' risk aversion has different degree of effects on the equilibrium results. The risk aversion of the manufacturer has a greater impact on quality, wholesale price, and the utilities of the manufacturer than that of the retailer, while the risk aversion of the retailer has a greater impact on the utilities of the retailer than that of the manufacturer. Moreover, it is interesting that their risk aversion has comparable effects on the retail price, demand, and the total utilities.

The remainder of the paper is organized as follows. The related literature is reviewed in Section 2 and then key assumptions and the general model are presented in Section 3. Section 4 investigates the optimal quality and price decisions of two Stackelberg models and analyzes the effects of risk aversion of players on the optimal decisions. In Section 5, we present a numerical study to verify the results in Section 4 and to illustrate some related issues. The paper concludes with Section 6 .

\section{Literature Review}

Our model is related to three recent streams of papers in the operations management literature: price and quality decision, risk management, and channel structure.

2.1. Price and Quality Decision. Many papers examined price and quality decision problems. The majority of these studies focused on the effect of supply chain contract, competition, and cooperation among the channels on the price and quality decision [8-12]. Banker et al. [8] developed a model of oligopolistic competition to investigate whether equilibrium levels of quality increase as competition intensifies. Gurnani et al. [18] studied the effect of the timing of price commitment decisions on the investment decisions and on the profits for the supplier and buyer with quality-effort dependent demand. Matsubayashi [9] considered a price and quality competition between two firms and analyzed the effect of differentiation and vertical integration in terms of the welfare of both firms and consumers. Xu [11] studied a joint pricing and product quality decision problem in a manufacturer-retailer relationship and showed that marginal revenue function is closely related to the distribution channel structures (directsell channel and indirect-sell channel).

It should be mentioned that, in the above papers, price and quality problems are studied under the assumption that all supply chain members are risk neutral. Being different from them, we investigate how the price and quality decisions are affected by the risk aversion of players.

2.2. Risk Management. Risk attitude has an important impact on supply chain members' decisions [1, 3, 19, 20]. Tsay [20] analyzed how risk sensitivity affects both sides of the manufacturer-retailer relationship under various scenarios of strategic power and how these dynamics are altered by a return policy and found that the penalty for ignoring risk sensitivity can be substantial. Gan et al. [21] investigated how a supply chain involving a risk-neutral supplier and a downside-risk-averse retailer can be coordinated with a supply contract. Xiao and Yang [4] developed a price-service competition model of two supply chains to investigate the 
effects of the retailers' risk sensitivity on the players' optimal strategies, where each supply chain consists of one riskneutral supplier and one risk-averse retailer. They did not concern the manufacturers' risk sensitivity, which is mainly studied in our model. Wu et al. [1] studied a supply contract model in a risk-averse environment with a conditional valueat-risk objective function and investigated the impact of risk aversion on the manufacturer's optimal decisions. Arcelus et al. [22] evaluated the pricing and ordering policies of a retailer, facing a price-dependent stochastic demand, within a newsvendor framework, under different degrees of risk tolerance and under a variety of optimizing objectives. Li et al. [23] studied the equilibrium contract strategies of two risk averse suppliers and two risk-neutral retailers. They focused on the impact of competition intensity and risk aversion on attitudes of the suppliers' contract choices. Xu et al. [24] investigated channel coordination for two-echelon fashion supply chain with risk-averse retailer and price-dependent demand.

In the above papers, the authors considered either the upstream firms or the downstream firms are risk averse in two-echelon supply chain or within a newsvendor framework. However, in reality, it is more reasonable that the upstream firms as well as the downstream firms are riskaverse decision makers under demand uncertainty. The risk aversion of one firm may not only affect its own decision but also affect the decisions of its supply chain members. Choi et al. [25] carried out a mean-variance analysis for a twoechelon supply chain under a returns policy. They studied both the cases with centralized and decentralized supply chains and illustrated how a returns policy can be applied for managing the supply chains to address the channel coordination and risk control. Xiao and Choi [26] developed a model of a two-echelon system consisting of two manufacturers and two retailers, where all players are risk averse. They explored the effects of risk sensitivity, pricing power, and purchasing option of the retailer on the channel structure strategies and wholesale prices of the manufacturers. Although the two papers above considered both the upstream firms and the downstream firms risk-averse in two-echelon supply chain, they are different from ours because we derive the optimal price and quality decisions under manufacturer Stackelberg and retailer Stackelberg structures with risk-averse players and investigate the respective effects of risk aversion of the manufacturer and retailer on equilibrium decisions and the channel structure strategies.

2.3. Channel Structure. Many researchers have examined the issues of supply chain channel structures. Choi [27] studied three noncooperative games of different power structures between the two manufacturers and the retailer, that is, two Stackelberg and one Nash game, and investigated the effect of cost differences on equilibrium prices and profits. Dong et al. [28] developed a game theoretic channel model of a manufacturer and a retailer under the two channel relationship structures and studied the impact of ER on purchase quantity, price, and the distribution of profits in three cases. $\mathrm{Wu}$ [14] examined the price and service level decision of a manufacturer-retailer supply chain in four channel strategies. Tang et al. [29] derived and compared the equilibrium price and service of a service supply chain under three different channel structures. Xiao et al. [30] investigated the product variety and channel structure strategies of manufacturer by a retailer Stackelberg pricing model. They considered the case where the manufacturer needs to select either the "single indirect channel" or the "dual channels." The aforementioned studies focused on a risk-neutral setting in which the chain members' objectives are to maximize expected profit or cost minimization. They ignored the decision makers' risk attitude.

As reviewed above, how the risk aversion of the manufacturer and the retailer, respectively, affects the players' price and quality decisions in MS and RS channel strategies is not yet fully known. In addition, it is important to know the different degree of effects of players' risk aversion on equilibrium results. To the best of our knowledge, the above important research issues have not yet been explored in the literature. Addressing these research questions, hence, outlines the contribution of this paper.

\section{Model Description}

Consider a two-echelon supply chain consisting of one risk-averse manufacturer and one risk-averse retailer facing uncertain demands. The manufacturer sells his products to consumers through the retailer. We discuss price and quality decisions of the two risk-averse decision makers in different models: manufacturer Stackelberg model (MS) and retailer Stackelberg model (RS).

We have the following notations:

$$
\begin{aligned}
& \widetilde{a} \text { : the stochastic market base for the retailer with } \\
& \text { mean } a \text {, variance } \sigma^{2} \text {; } \\
& c \text { : the unit production cost of the manufacturer, } a \geq \\
& c>0 \text {; } \\
& b \text { : the demand sensitivity to the retail price; } \\
& \alpha \text { : the demand sensitivity to the quality of the product; } \\
& p \text { : the retail price of the product; } \\
& x \text { : the quality level of the product; } \\
& w \text { : the wholesale price of the product; } \\
& r \text { : the quality cost coefficient. }
\end{aligned}
$$

Similar to the prior literature $[8,31]$, we assume that the demand function is

$$
D=\widetilde{a}-b p+\alpha x .
$$

Here we assume the demand is more sensitive to price than to quality; that is, $b>\alpha$. Furthermore, we assume that when the manufacturer provides a quality level $x$, similar to $[32,33]$, the quality cost of the manufacturer is $(1 / 2) r x^{2}$, which assures that the profit function is concave on $x$; that is, improving quality has a decreasing return on quality expenditure [8]. The larger the coefficient $r$, the lower the quality improvement efficiency $(1 / r)$ of the manufacturer. 
The unit production cost of the retailer is normalized to zero, which will have no influence on our results. Each player has perfect information of the demand and the cost structures when there is no collusion or cooperation. For the sake of simplicity, we assume $a>b c$. This assumption, which is similar to the ones made by Appelbaum and Lim [34] and by Spencer and Brander [35], implies that, for every realization of demand, there exists a nonzero quantity of output for which the market clearing price is greater than the marginal cost of production [32]. This assumption allows us to avoid consideration of situations in which the retailer optimally responds to low realizations of demand by selling nothing.

Note that, in the model of demand function, the manufacturer can influence the demand by setting the wholesale price and the quality improvement [36]. Meanwhile, the retailer can independently influence the retail price of the product.

Then, the random profit of the manufacturer is

$$
\Pi_{m}=(w-c)(\tilde{a}-b p+\alpha x)-\frac{1}{2} r x^{2} .
$$

The random profit of the retailer is

$$
\Pi_{r}=(p-w)(\widetilde{a}-b p+\alpha x)
$$

Considering the risk aversion of the manufacturer and the retailer, similar to Xiao and Yang [4] and Xie et al. [13], we assume that each player assesses his utility via the following mean-variance value function of his random profit:

$$
U_{i}\left(\Pi_{i}\right)=E\left(\Pi_{i}\right)-\frac{\lambda_{i}}{2} \operatorname{Var}\left(\Pi_{i}\right)
$$

where the first term is the expected profit of the player, the second term is the risk cost of the player, and $\lambda_{i}$ is the constant absolute risk aversion (CARA) of the player. The larger the player's risk aversion $\lambda_{i}$ is, the more conservative his behavior will be. Obviously, the player will make a trade-off between the mean and the variance of his random profit.

With the equation above, we can then study the impact of risk aversion on price and quality decisions in different models.

\section{Equilibrium Decisions under Different Supply Chain Structures}

In this section, we explore price and quality decisions in two different models, that is, manufacturer Stackelberg model (MS) and retailer Stackelberg model (RS). In the MS and RS models, the manufacturer and the retailer make their own decisions to maximize their individual utilities.
According to (2), (3), and (4), we can express and derive the utility function of the manufacturer and the retailer as follows:

$$
\begin{aligned}
U_{m}\left(\Pi_{m}\right) & =E\left(\Pi_{m}\right)-\frac{\lambda_{m}}{2} \operatorname{Var}\left(\Pi_{m}\right) \\
& =(w-c)(a-b p+\alpha x)-\frac{1}{2} r x^{2}-\frac{\lambda_{m}(w-c)^{2} \sigma^{2}}{2}, \\
U_{r}\left(\Pi_{r}\right) & =E\left(\Pi_{r}\right)-\frac{\lambda_{r}}{2} \operatorname{Var}\left(\Pi_{r}\right) \\
& =(p-w)(a-b p+\alpha x)-\frac{\lambda_{r}(p-w)^{2} \sigma^{2}}{2} .
\end{aligned}
$$

Next, based on the general models, the equilibrium results of the decision variables will be provided and the impact of risk aversion of the players on equilibrium decisions will be examined in different models.

4.1. Manufacturer Stackelberg Model. In the case of manufacturer Stackelberg model, the manufacturer, as the Stackelberg leader, determines simultaneously the wholesale price $w$ and quality $x$ in the first step. The retailer observes the decisions made by the manufacturer and makes his response to set his optimal retail price $p$ as the follower.

In order to determine the Stackelberg equilibrium by backward induction, we first solve the retailer's optimal problem when the manufacturer's decision variables $w$ and $x$ are given:

$$
\operatorname{Max} U_{r}\left(\Pi_{r}\right)=(p-w)(a-b p+\alpha x)-\frac{\lambda_{r}(p-w)^{2} \sigma^{2}}{2}
$$

Since $\partial^{2} U_{r}\left(\Pi_{r}\right) / \partial p^{2}=-2 b-\lambda_{r} \sigma^{2}<0$, the utility function is strictly concave in retail price.

Solving the first-order condition of (6), we find that the optimal retail price is

$$
p^{*}=\frac{a+\left(b+\sigma^{2} \lambda_{r}\right) w+\alpha x}{2 b+\sigma^{2} \lambda_{r}} .
$$

Using the retailer's reaction function, we can derive the manufacturer's optimal wholesale price and quality. This is carried out by maximizing the manufacturer's utilities shown in (8), given $p^{*}$ in (7)

$$
\begin{array}{r}
\operatorname{Max} U_{m}\left(\Pi_{m}\right)=(w-c)\left[a-b \cdot \frac{a+\left(b+\sigma^{2} \lambda_{r}\right) w+\alpha x}{2 b+\sigma^{2} \lambda_{r}}\right. \\
+\alpha x]-\frac{1}{2} r x^{2}-\frac{\lambda_{m}(w-c)^{2} \sigma^{2}}{2} .
\end{array}
$$


Hessian matrix of $U_{m}\left(\Pi_{m}\right)$ is

$$
H_{1}=\left[\begin{array}{cc}
-\frac{2 b\left(b+\lambda_{r} \sigma^{2}\right)}{2 b+\lambda_{r} \sigma^{2}}-\lambda_{m} \sigma^{2} & \frac{\alpha\left(b+\lambda_{r} \sigma^{2}\right)}{2 b+\lambda_{r} \sigma^{2}} \\
\frac{\alpha\left(b+\lambda_{r} \sigma^{2}\right)}{2 b+\lambda_{r} \sigma^{2}} & -r
\end{array}\right] .
$$

The utility function $U_{m}\left(\Pi_{m}\right)$ is a concave function on $(w, x)$ if and only if Hessian matrix is negative definite. Define $\widehat{r}_{1}=$ $\left[\alpha\left(b+\lambda_{r} \sigma^{2}\right)\right]^{2} /\left(2 b+\lambda_{r} \sigma^{2}\right)\left[2 b\left(b+\lambda_{r} \sigma^{2}\right)+\lambda_{m} \sigma^{2}\left(2 b+\lambda_{r} \sigma^{2}\right)\right]$.

Solving the first-order condition of (8), we derive the following proposition. Proofs of all propositions are given in Appendix A.

Proposition 1. If $r>\widehat{r}_{1}$, then the optimal wholesale price and quality of the product are

$$
\begin{aligned}
w^{M S *}= & +r(a-b c)\left(b+\lambda_{r} \sigma^{2}\right)\left(2 b+\lambda_{r} \sigma^{2}\right) \\
\times & \left(2 b \lambda_{r} \sigma^{2}\left(3 r b-\alpha^{2}\right)+b^{2}\left(4 r b-\alpha^{2}\right)\right. \\
& \left.+\lambda_{r}^{2} \sigma^{4}\left(2 r b-\alpha^{2}\right)+r \sigma^{2} \lambda_{m}\left(2 b+\lambda_{r} \sigma^{2}\right)^{2}\right)^{-1} \\
x^{M S *}=\alpha & (a-b c)\left(b+\lambda_{r} \sigma^{2}\right)^{2} \\
\times & \left(2 b \lambda_{r} \sigma^{2}\left(3 r b-\alpha^{2}\right)+b^{2}\left(4 r b-\alpha^{2}\right)\right. \\
& \left.+\lambda_{r}^{2} \sigma^{4}\left(2 r b-\alpha^{2}\right)+r \sigma^{2} \lambda_{m}\left(2 b+\lambda_{r} \sigma^{2}\right)^{2}\right)^{-1}
\end{aligned}
$$

and the optimal retail price is

$$
p^{M S *}=\frac{a+\left(b+\sigma^{2} \lambda_{r}\right) w^{M S *}+\alpha x^{M S *}}{2 b+\sigma^{2} \lambda_{r}} .
$$

In Proposition 1, the condition $r>\widehat{r}_{1}$ assures that the solution satisfying the first-order condition of $U_{m}\left(\Pi_{m}\right)$ is optimal. The condition $r>\widehat{r}_{1}$ means that the quality investment should not be too inexpensive, which is consistent with those made in Tsay and Agrawal [37], Gilbert and Cvsa [32], and Xiao and Yang [4].

Next, we study the effect of risk aversion on equilibrium decisions in MS scenario. Solving the first-order conditions of $w^{\mathrm{MS} *}, x^{\mathrm{MS} *}$, and $p^{\mathrm{MS} *}$, we derive the following.

Proposition 2. In a MS strategy, we have the following.

(1) The optimal decisions, including the wholesale price and quality of the product and the retail price, all decrease with the risk aversion of the manufacturer; namely, $\partial w^{M S *} / \partial \lambda_{m}<0, \partial x^{M S *} / \partial \lambda_{m}<0$, and $\partial p^{M S *} / \partial \lambda_{m}<0$.

(2) The wholesale price and quality of the product increase with the risk aversion of the retailer, while the retail price decreases with the risk aversion of the retailer; namely, $\partial w^{M S *} / \partial \lambda_{r}>0, \partial x^{M S *} / \partial \lambda_{r}>0$, and $\partial p^{M S *} / \partial \lambda_{r}<0$.
Proposition 2 implies the following, in a strategy of MS.

(1) The higher the risk aversion of the manufacturer is, the lower the wholesale price, quality, and retail price will be. The reason is that when the manufacturer becomes more risk averse, the manufacturer will prefer lowering the wholesale price to stimulate a higher demand and lowering the quality level to save the investment cost. Meanwhile, for the retailer, the wholesale price is lower; the retailer can set a lower price. Thus, the demand will increase such that the risk of demand uncertainty for the manufacturer decreases. Otherwise, the lower the risk aversion of the manufacturer is, the higher the wholesale price, quality, and retail price will be. A risk-averse manufacturer sets a lower wholesale price and quality than those of a risk-neutral manufacturer.

(2) The lower the risk aversion of the retailer is, the higher the retail price will be while the lower the wholesale price and quality will be. The reason is that when the risk aversion of the retailer decreases, the retailer, who is less risk averse, will set a higher retail price. As a result, the demand of the product will decrease. Since the manufacturer is a riskaverse decision maker, the expected decreased demand will induce the manufacturer to lower wholesale price to spur the demand and lower the quality level to save investment cost. This in turn creates more demand; as a result, the risk of demand uncertainty for the manufacturer decreases. Otherwise, the higher the risk aversion of the retailer is, the lower the retail price will be while the higher the wholesale price and quality will be. A risk-averse retailer sets a lower price than that of a risk-neutral retailer.

(3) The retailer may reveal lower risk aversion than his real risk aversion so that he will pay a lower wholesale price and gain more utilities, which will hurt the manufacturer's interests. Since the retailer has incentives to reveal false risk aversion information, the manufacturer should design mechanisms to induce him to reveal actual information in MS strategy.

(4) The wholesale price and quality are mutually complementary, that is, a "high quality and high price" pricing strategy [37].

Proposition 3. In a MS strategy, the optimal decisions, including the wholesale price, quality, and the retail price, all decrease with the quality cost coefficient; namely, $\partial x^{M S *} / \partial r<0$, $\partial w^{M S *} / \partial r<0$, and $\partial p^{M S *} / \partial r<0$.

When the quality cost coefficient increases, the quality investment becomes more expensive such that the manufacturer would like to undercut the quality improvement to save investment, and, meanwhile, lower the wholesale price. In that case, the retailer will set a lower retail price. Otherwise, the wholesale price, quality, and the retail price will be higher when the quality cost coefficient decreases.

4.2. Retailer Stackelberg Model. In the case of retailer Stackelberg model, the retailer, as the Stackelberg leader, determines price markup $m(=p-w)$ in the first step. The manufacturer observes the decision made by the retailer and makes his response to set his optimal wholesale price and quality as the 
follower. Similar game-theoretic framework as applied in the MS model is implemented to solve this problem; that is, the problem is solved backwards.

We first solve the manufacturer's optimal problem when the retailer's decision variable $m$ is given:

$$
\begin{aligned}
\operatorname{Max} U_{m}\left(\Pi_{m}\right)= & (w-c)[a-b(w+m)+\alpha x]-\frac{1}{2} r x^{2} \\
& -\frac{\lambda_{m}(w-c)^{2} \sigma^{2}}{2} .
\end{aligned}
$$

Hessian matrix of $U_{m}\left(\Pi_{m}\right)$ is

$$
H_{2}=\left[\begin{array}{cc}
-2 b-\lambda_{m} \sigma^{2} & \alpha \\
\alpha & -r
\end{array}\right]
$$

The utility function $U_{m}\left(\Pi_{m}\right)$ is a concave function on $(w, x)$ if and only if Hessian matrix is negatively definited. Define $\widehat{r}_{2}=\alpha^{2} /\left(2 b+\lambda_{m} \sigma^{2}\right)$.

Solving the first-order condition of (12), we derive the optimal wholesale price and quality of the product if $r>\widehat{r}_{2}$. Consider

$$
\begin{gathered}
w^{*}=\frac{c\left(b r-\alpha^{2}\right)+r(a-b m)+c \lambda_{m} \sigma^{2} r}{-\alpha^{2}+2 b r+\lambda_{m} \sigma^{2} r} \\
x^{*}=\frac{\alpha(a-b m-b c)}{-\alpha^{2}+2 b r+\lambda_{m} \sigma^{2} r}
\end{gathered}
$$

Using the manufacturer's reaction function, we can derive the optimal price markup. This is carried out by maximizing the utilities of the retailer shown in (16), given $w^{*}$ in (14) and $x^{*}$ in (15):

$$
U_{r}\left(\Pi_{r}\right)=m\left[a-b\left(w^{*}+m\right)+\alpha x^{*}\right]-\frac{\lambda_{r}}{2} m^{2} \sigma^{2} .
$$

The second-order condition of $(16) \partial^{2} U_{r}\left(\Pi_{r}\right) / \partial m^{2}<0$. Therefore, the utility function $U_{r}\left(\Pi_{r}\right)$ is strictly concave in price markup.

Solving the first-order condition of (16), we derive the optimal price markup:

$$
m^{\mathrm{RS} *}=\frac{r(a-b c)\left(b+\lambda_{m} \sigma^{2}\right)}{2 b r\left(b+\lambda_{m} \sigma^{2}\right)+\sigma^{2} \lambda_{r}\left(2 b r-\alpha^{2}\right)+\lambda_{m} \lambda_{r} \sigma^{4} r} .
$$

Proposition 4. If $r>\widehat{r}_{2}$, then the optimal wholesale price and quality of the product are

$$
\begin{gathered}
w^{R S *}=\frac{c\left(b r-\alpha^{2}\right)+r\left(a-b m^{R S *}\right)+c \lambda_{m} \sigma^{2} r}{-\alpha^{2}+2 b r+\lambda_{m} \sigma^{2} r}, \\
x^{R S *}=\frac{\alpha\left(a-b m^{R S *}-b c\right)}{-\alpha^{2}+2 b r+\lambda_{m} \sigma^{2} r}
\end{gathered}
$$

and the optimal retail price is

$$
p^{R S *}=w^{R S *}+m^{R S *} .
$$

According to Proposition 4, we study the effect of $\lambda_{m}$ and $\lambda_{r}$ on the equilibrium decisions in RS model.

Proposition 5. In a RS strategy, consider the following.

(1) The optimal decisions, including the wholesale price, quality, and the retail price of the product, all decrease with the risk aversion of the manufacturer; namely, $\partial w^{R S *} / \partial \lambda_{m}<0, \partial x^{R S *} / \partial \lambda_{m}<0$, and $\partial p^{R S *} / \partial \lambda_{m}<0$.

(2) Both the wholesale price and quality increase with the risk aversion of the retailer, while the retail price decreases with the risk aversion of the retailer; namely, $\partial w^{R S *} / \partial \lambda_{r}>0, \partial x^{R S *} / \partial \lambda_{r}>0$, and $\partial p^{R S *} / \partial \lambda_{r}<0$.

For the RS model, we can derive similar proposition and obtain similar observations. The only difference between RS model and MS model is that in MS model the retailer may conceal his real risk aversion while in RS model the manufacturer may do that. Since the manufacturer makes his decision after the retailer, he may have an incentive to conceal his real risk aversion and report a more beneficial risk aversion to gain more utilities. Therefore, the retailer should design mechanisms to induce the manufacturer to reveal actual information in a RS strategy.

Proposition 6. In a RS strategy, the optimal decisions, including the wholesale price, quality, and the retail price, all decrease with the quality cost coefficient; namely, $\partial x^{R S *} / \partial r<0$, $\partial w^{R S *} / \partial r<0$, and $\partial p^{R S *} / \partial r<0$.

Similar to Proposition 3, the quality cost coefficient in RS has the same effect on the equilibrium wholesale price, quality, and retail price as that in MS.

\section{Numerical Study}

We use several numerical examples to illustrate and verify the effects of risk aversion on players' equilibrium decisions and to compare the equilibrium results in the two models. We assume the default values of parameters are as follows: $a=500, b=10, \alpha=8, c=3, r=100$, and $\sigma=60$. When examining the impact of $\lambda_{m}\left(\lambda_{r}\right)$ on the equilibrium decisions, we allow $\lambda_{m}\left(\lambda_{r}\right)$ to vary in the range of $[0,1]$ and set $\lambda_{r}\left(\lambda_{m}\right)$ as a constant, $\lambda_{r}\left(\lambda_{m}\right)=0.02$.

\subsection{The Effects of $\lambda_{m}$ on Equilibrium Results}

5.1.1. The Effects of $\lambda_{m}$ on Optimal Decisions. Figures 13 illustrate how the optimal wholesale price, quality, and retail price depend on the risk aversion of the manufacturer. From Figures 1-3, we find that the optimal wholesale price, quality, and retail price all decrease with the risk aversion of the manufacturer $\lambda_{m}$ in MS and RS models. When the manufacturer behaves more risk-aversely while facing demand uncertainty, he would like to undercut wholesale price and lower quality level to save investment such that the retailer would like to lower the retail price to attract more customers. 


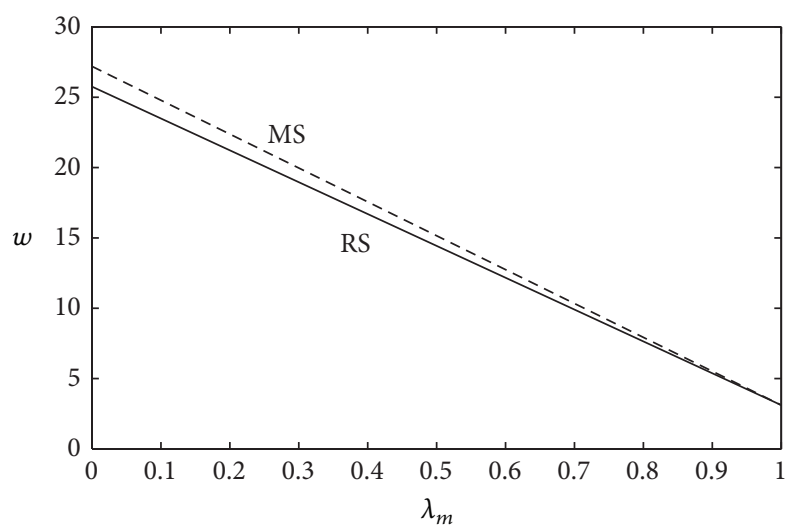

FIGURE 1: Impact of risk aversion of the manufacturer on the wholesale price.

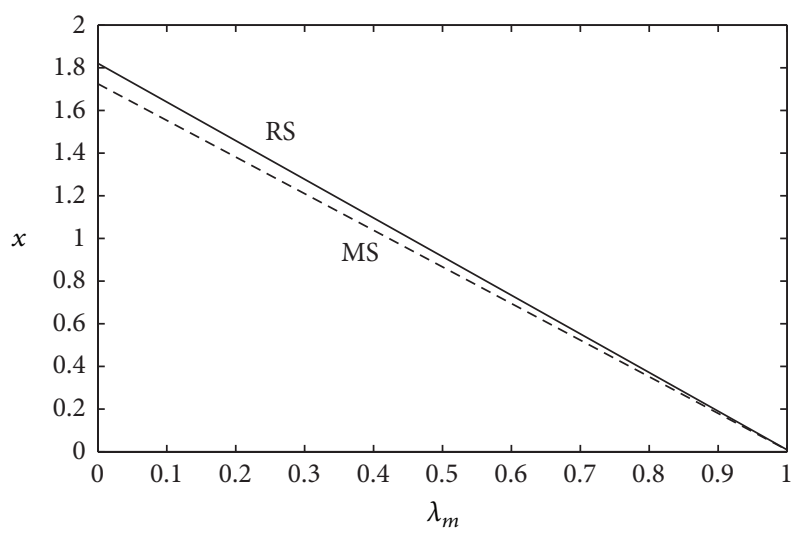

FIGURE 2: Impact of risk aversion of the manufacturer on quality.

5.1.2. The Effects of $\lambda_{m}$ on Demand and Utility. Figure 4 illustrates the effects of the risk aversion of the manufacturer on demand. From Figure 4, we find that the demand increases with $\lambda_{m}$ in MS and RS models, which is caused by the decreasing price. Figures 5-7 illustrate the effects of the risk aversion of the manufacturer on the utilities of the manufacturer, the utilities of the retailer, and the total utilities of the supply chain, respectively. The utilities of the manufacturer decrease with $\lambda_{m}$ while the utilities of the retailer increase with $\lambda_{m}$. This implies that when the manufacturer is more conservative, the utilities of the manufacturer will decrease while the utilities of the retailer will increase. Since the effect of $\lambda_{m}$ on utilities of the retailer is much smaller than that on utilities of the manufacturer, the total utilities of the supply chain decrease with $\lambda_{m}$.

\subsection{The Effects of $\lambda_{r}$ on Equilibrium Results}

5.2.1. The Effects of $\lambda_{r}$ on Optimal Decisions. Figures 8-10 illustrate how the optimal wholesale price, quality, and retail price depend on the risk aversion of the retailer. From Figures 8 and 9, we find that as the risk aversion of the retailer $\lambda_{r}$ increases, the manufacturer sets a higher wholesale price and a higher quality in MS and RS. Figure 10 shows that the

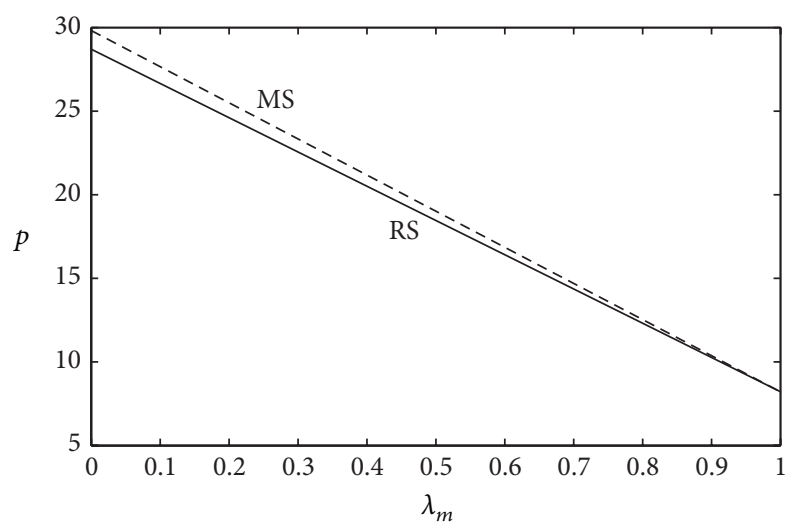

FIGURE 3: Impact of risk aversion of the manufacturer on the retail price.

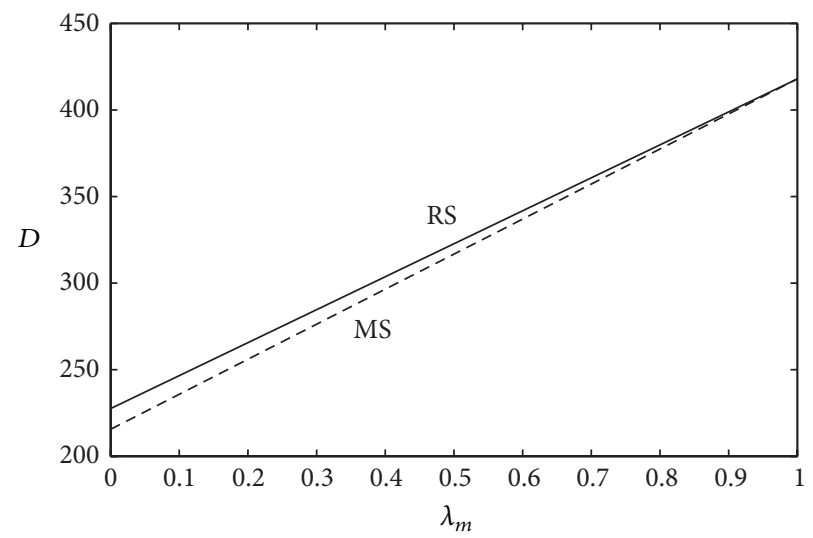

FIGURE 4: Impact of risk aversion of the manufacturer on demand.

optimal retail price decreases with $\lambda_{r}$ in the two models, which indicates that a retailer with higher risk aversion tends to set a lower price.

5.2.2. The Effects of $\lambda_{r}$ on Demand and Utility. Figure 11 illustrates the effects of risk aversion of the retailer on demand. From Figure 11, we find that the demand increases with $\lambda_{r}$ in MS and RS models, which is caused by the decreasing price. Figures 12-14 illustrate the effects of the risk aversion of the retailer on the utilities of the manufacturer, the utilities of the retailer, and the total utilities of the supply chain, respectively. The utilities of the manufacturer increase with $\lambda_{r}$ while the utilities of the retailer decrease with $\lambda_{r}$. This implies that when the retailer is more conservative, the utilities of the retailer will become less while the utilities of the manufacturer will become more. Since the effect of $\lambda_{r}$ on utilities of the retailer is much larger than that on utilities of the manufacturer, the total utilities of the supply chain decrease with $\lambda_{r}$. 


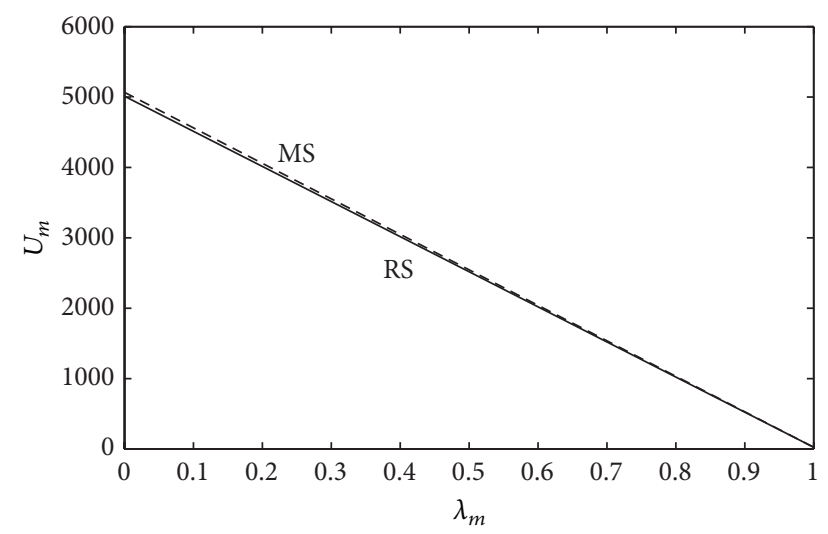

FIGURE 5: Impact of risk aversion of the manufacturer on utilities of the manufacturer.

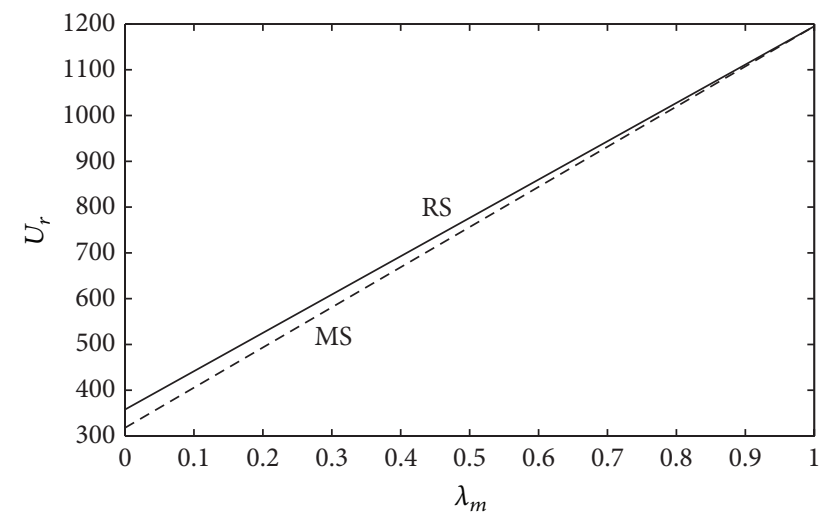

FIGURE 6: Impact of risk aversion of the manufacturer on utilities of the retailer.

\subsection{Comparison}

5.3.1. Comparison of Equilibrium Results in Different Supply Chain Strategies. Since the equilibrium results are complicated, it is analytically intractable to compare them in different models for managerial insights. We now compare the optimal decisions, demand, and utilities shown in our numerical study, though we have no mathematical proof on hand.

We firstly compare the optimal decisions in the two models. From Figures 1 and 8, we find that the wholesale price in MS is higher than that in RS; that is, $w^{\mathrm{MS} *}>w^{\mathrm{RS} *}$. Moreover, although the wholesale price is affected by the risk aversion of both the manufacturer and the retailer, the impact of the risk aversion of the manufacturer is more dramatic. From Figures 2 and 9, we know that $x^{\mathrm{RS} *}>x^{\mathrm{MS} *}$. The manufacturer, as the leader, would like to set higher price and lower quality in MS model than in RS model. We also find that the effect of $\lambda_{m}$ on quality is much larger than that of $\lambda_{r}$ and the effect of $\lambda_{r}$ on the product quality is very small. We find that $p^{\mathrm{MS} *}>p^{\mathrm{RS} *}$ in Figure 3 while $p^{\mathrm{RS} *}>p^{\mathrm{MS} *}$ in Figure 10, which indicates that the difference between $p^{\mathrm{MS} *}$ and $p^{\mathrm{RS} *}$ varies with the value of $\lambda_{m}$ and $\lambda_{r}$. Besides, we find that $\lambda_{m}$

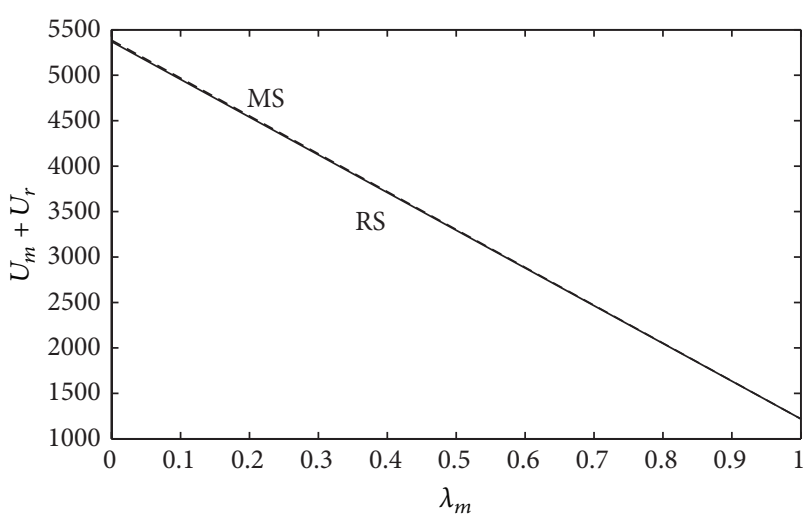

FIgURE 7: Impact of risk aversion of the manufacturer on total utilities.

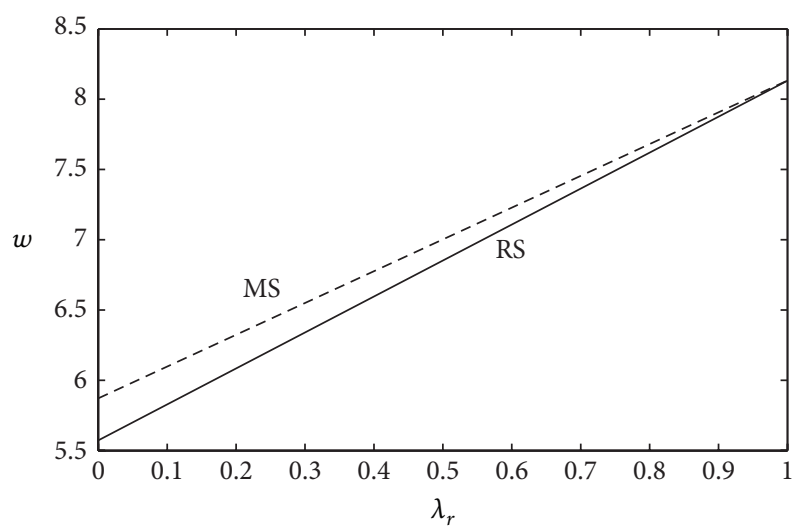

FIGURE 8: Impact of risk aversion of the retailer on the wholesale price.

and $\lambda_{r}$ have comparable effects on the retail price in MS and RS models.

From Figures 4 and 11, we find that the difference between $D^{\mathrm{MS} *}$ and $D^{\mathrm{RS} *}$ is also uncertain and varies with the value of $\lambda_{m}$ and $\lambda_{r}$. From Figures 5, 6, 12, and 13, the utilities of the manufacturer are higher in MS than in RS while the utilities of the retailer are higher in RS than in MS, which indicates that the player who acts as a leader can gain more utilities. The risk aversion of the manufacturer has a greater impact on the utilities of the manufacturer than the risk aversion of the retailer, whereas the risk aversion of the retailer has a greater impact on the utilities of the retailer than the risk aversion of the manufacturer. Figures 7 and 14 show that the difference between $U^{\mathrm{MS} *}$ and $U^{\mathrm{RS} *}$ is very small and is hardly influenced by the risk aversion of the manufacturer and retailer. Besides, we find that $\lambda_{m}$ and $\lambda_{r}$ have comparable effects on the total utilities in MS and RS models.

5.3.2. Comparison with the Original Model. We compare the analysis results above with those obtained in Xie et al. [13] that used the similar models. For convenience, we use the expression of upstream and downstream to describe the firms. We obtain the same effects of risk aversion of the 


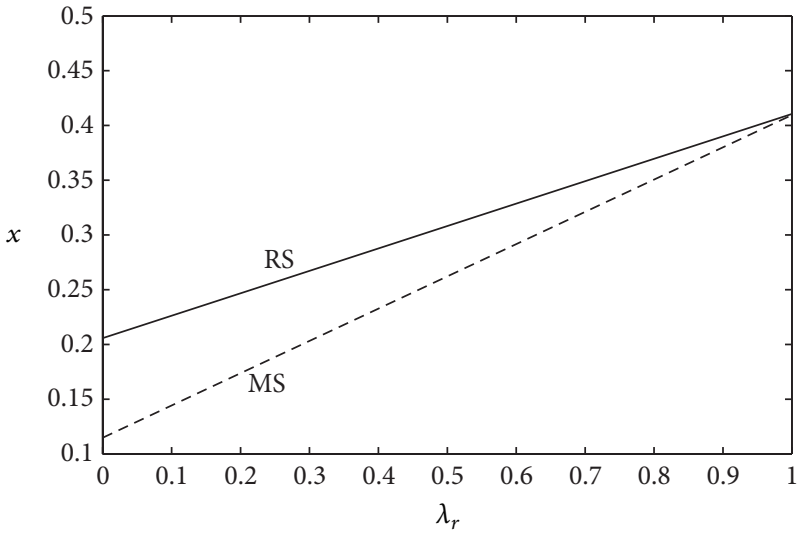

FIGURE 9: Impact of risk aversion of the retailer on the quality.

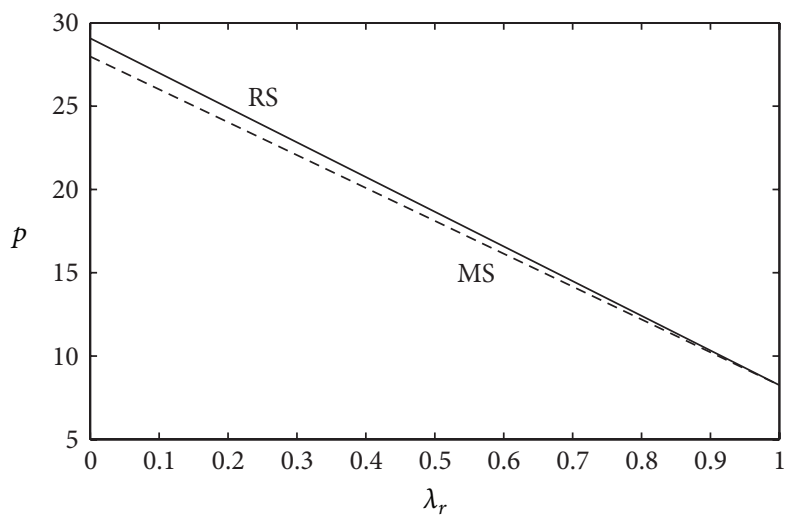

FIGURE 10: Impact of risk aversion of the retailer on the retail price.

downstream on the equilibrium results as Xie et al. [13], except for the impacts on the wholesale price and quality.

However, we obtain some new results. Firstly, we find that the wholesale price and quality both increase with the risk aversion of the downstream in the two models. Secondly, our results show that the risk aversion of the upstream has major impact on the optimal wholesale price, retail price, and quality decisions. However, Xie et al. [13] derived that the retail price and quality are not related to the risk aversion of the upstream firm. Moreover, we derive the impact of risk aversion of the upstream on demand and utilities of the players. Thirdly, we illustrate the different degree of effects of risk aversion of the upstream and downstream on equilibrium results. The wholesale price and quality decisions are mainly influenced by the risk aversion of the upstream. In addition, the risk aversion of the upstream and downstream has comparable effects on the retail price, demand, and total utilities in the two models. Last but not least, unlike Xie et al. [13], in our model, the utility of the upstream firm will not become negative as the downstream firm becomes less risk averse.

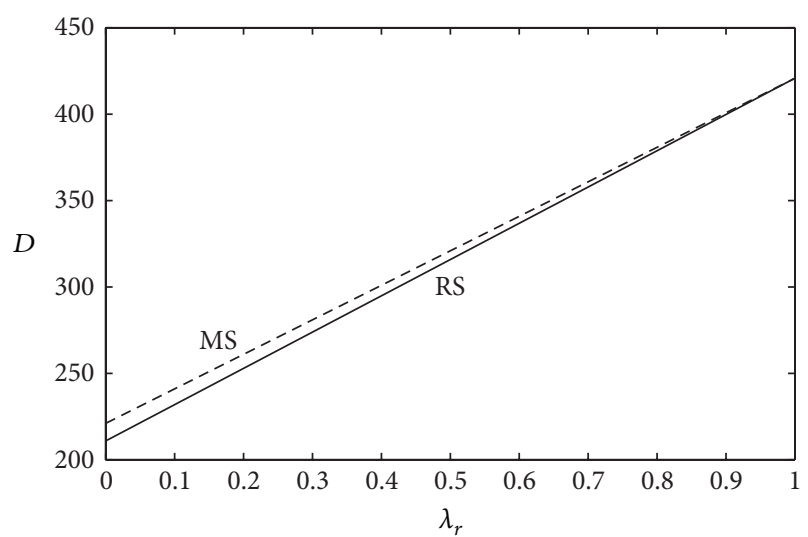

FIGURE 11: Impact of risk aversion of the retailer on demand.

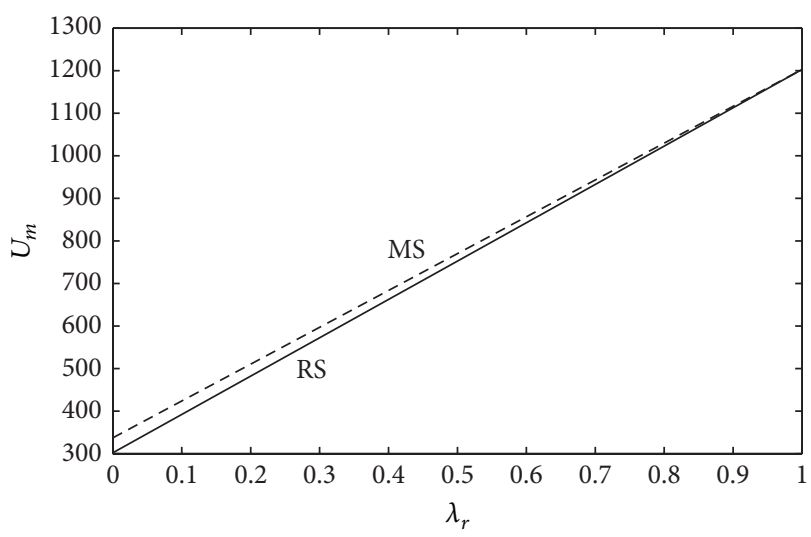

FIGURE 12: Impact of risk aversion of the retailer on utilities of the manufacturer.

\section{Conclusion}

This paper addresses optimal price and quality decisions in a manufacturer-retailer supply chain under demand uncertainty, where both players are risk averse. By means of game theory, we employ the constant absolute risk aversion (CARA) function to analyze two different supply chain structures, that is, manufacturer Stackelberg model (MS) and retailer Stackelberg model (RS). We then analyze the results and discuss the effect of risk aversion of the manufacturer and retailer upon the equilibrium decisions.

We adopt a model recently published by Xie et al. [13] and introduce the wholesale price as a new decision variable. This modification of the original model enables us to abandon the restrictive assumption of constant wholesale price previously used in decentralized equilibriums. Thus, we propose some new interesting managerial implications in such a case.

Our results imply that risk aversion of both the manufacturer and the retailer has significant effects on the price and quality decisions, whereas the results from the original model predict that only the risk tolerance of the downstream affects the equilibrium results. We find that, in general, in MS and RS models, the optimal wholesale price, quality, and retail price of the product all decrease with the risk aversion of 


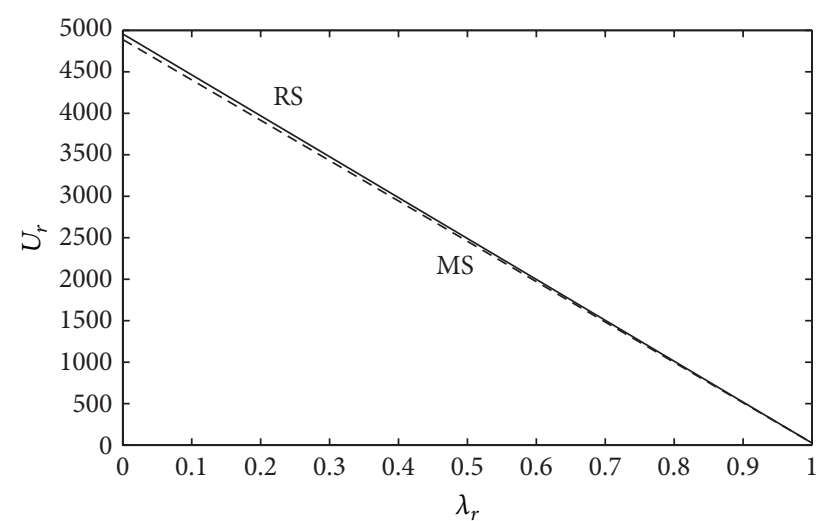

FIGURE 13: Impact of risk aversion of the retailer on utilities of the retailer.

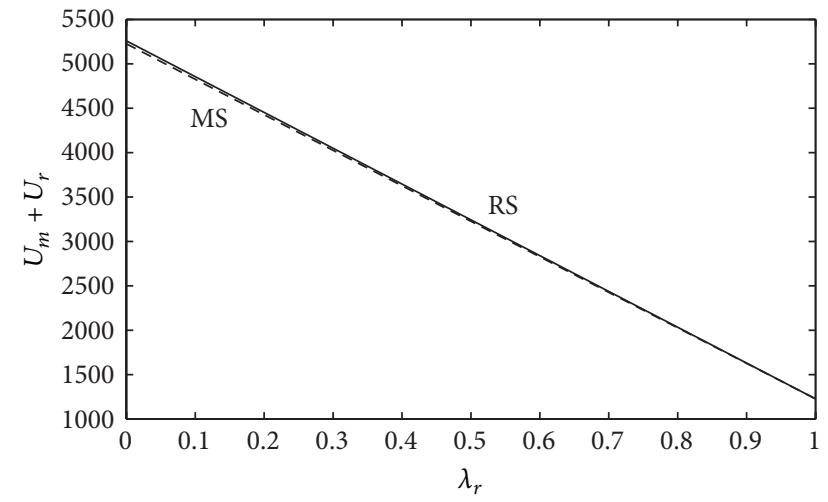

FIGURE 14: Impact of risk aversion of the retailer on total utilities.

the manufacturer. Additionally, both the wholesale price and quality increase with the risk aversion of the retailer, while the retail price decreases with the risk aversion of the retailer. This paper suggests that the wholesale price, quality, and retail price all decrease with the quality cost coefficient.

The numerical study indicates that the utilities of the manufacturer as well as the retailer decrease with his own risk aversion but increase with the other member's risk aversion. Moreover, the total utilities of the supply chain decrease with both the players' risk aversion. Our results show that the manufacturer and the retailer can take advantage of channel leadership to gain more utility. In addition, the two players' risk aversion has different degree of effects on the equilibrium results. The risk aversion of the manufacturer has a greater impact on quality, wholesale price, and utilities of the manufacturer than that of the retailer, while the risk aversion of the retailer has a greater impact on utilities of the retailer than that of the manufacturer. Moreover, it is interesting that their risk aversion has comparable effects on the retail price, demand, and the total utilities. Consequently, the firm should not ignore the impact of risk aversion of his upstream or downstream on the optimal decisions.

There are several directions for future research. Firstly, we assume a linear demand function extending this model by changing the demand function may yield some more interesting results. Secondly, instead of assuming that the supply chain consists of only one manufacturer and one retailer in this paper, we will allow two competing supply chains or multiple competing retailers to investigate the effect of the risk aversion of the rival on price and quality decisions in the future. Finally, this paper assumes that the risk aversion of players is common knowledge; it will be interesting to consider a system with asymmetric information.

\section{Appendices}

\section{A. Proof of Proposition 1}

Since $\partial^{2} U_{r}\left(\Pi_{r}\right) / \partial p^{2}=-2 b-\lambda_{r} \sigma^{2}<0$, the utility function is strictly concave in retail price. Solving the first-order condition of $U_{r}\left(\Pi_{r}\right)$, we find that the optimal retail price is

$$
p^{*}=\frac{a+\left(b+\sigma^{2} \lambda_{r}\right) w+\alpha x}{2 b+\sigma^{2} \lambda_{r}} .
$$

Inserting (A.1) into the manufacturer's utilities, we obtain

$$
\begin{aligned}
& \operatorname{Max}_{m}\left(\Pi_{m}\right) \\
& =(w-c)\left[a-b \cdot \frac{a+\left(b+\sigma^{2} \lambda_{r}\right) w+\alpha x}{2 b+\sigma^{2} \lambda_{r}}+\alpha x\right] \\
& \quad-\frac{1}{2} r x^{2}-\frac{\lambda_{m}(w-c)^{2} \sigma^{2}}{2} .
\end{aligned}
$$

Hessian matrix of $U_{m}\left(\Pi_{m}\right)$ is

$$
H_{1}=\left[\begin{array}{cc}
-\frac{2 b\left(b+\lambda_{r} \sigma^{2}\right)}{2 b+\lambda_{r} \sigma^{2}}-\lambda_{m} \sigma^{2} & \frac{\alpha\left(b+\lambda_{r} \sigma^{2}\right)}{2 b+\lambda_{r} \sigma^{2}} \\
\frac{\alpha\left(b+\lambda_{r} \sigma^{2}\right)}{2 b+\lambda_{r} \sigma^{2}} & -r
\end{array}\right]
$$

The utility function $U_{m}\left(\Pi_{m}\right)$ is a concave function on $(w, x)$ if and only if Hessian matrix is negatively definited. Define $\widehat{r}_{1}=\left[\alpha\left(b+\lambda_{r} \sigma^{2}\right)\right]^{2} /\left(2 b+\lambda_{r} \sigma^{2}\right)\left[2 b\left(b+\lambda_{r} \sigma^{2}\right)+\right.$ $\left.\lambda_{m} \sigma^{2}\left(2 b+\lambda_{r} \sigma^{2}\right)\right]$.

The first-order conditions of $U_{m}\left(\Pi_{m}\right)$ are

$$
\begin{aligned}
& \frac{\partial U_{m}\left(\Pi_{m}\right)}{\partial w}= a-b \cdot \frac{a+\left(b+\sigma^{2} \lambda_{r}\right) w+\alpha x}{2 b+\sigma^{2} \lambda_{r}} \\
&+\alpha x-(w-c) \cdot \frac{b\left(b+\sigma^{2} \lambda_{r}\right)}{2 b+\sigma^{2} \lambda_{r}} \\
&-\lambda_{m}(w-c) \sigma^{2}=0, \\
& \frac{\partial U_{m}\left(\Pi_{m}\right)}{\partial x}=(w-c) \cdot\left(\frac{-b \alpha}{2 b+\sigma^{2} \lambda_{r}}+\alpha\right)-r x=0 .
\end{aligned}
$$


Solving (A.4), we obtain

$$
\begin{aligned}
w^{\mathrm{MS} *}= & c+r(a-b c)\left(b+\lambda_{r} \sigma^{2}\right)\left(2 b+\lambda_{r} \sigma^{2}\right) \\
\times & \left(2 b \lambda_{r} \sigma^{2}\left(3 r b-\alpha^{2}\right)+b^{2}\left(4 r b-\alpha^{2}\right)\right. \\
& \left.+\lambda_{r}^{2} \sigma^{4}\left(2 r b-\alpha^{2}\right)+r \sigma^{2} \lambda_{m}\left(2 b+\lambda_{r} \sigma^{2}\right)^{2}\right)^{-1}, \\
x^{\mathrm{MS} *}=\alpha & (a-b c)\left(b+\lambda_{r} \sigma^{2}\right)^{2} \\
\times & \left(2 b \lambda_{r} \sigma^{2}\left(3 r b-\alpha^{2}\right)+b^{2}\left(4 r b-\alpha^{2}\right)\right. \\
& \left.+\lambda_{r}^{2} \sigma^{4}\left(2 r b-\alpha^{2}\right)+r \sigma^{2} \lambda_{m}\left(2 b+\lambda_{r} \sigma^{2}\right)^{2}\right)^{-1} .
\end{aligned}
$$

Inserting them into (A.1), we obtain the optimal retail price:

$$
p^{\mathrm{MS} *}=\frac{a+\left(b+\sigma^{2} \lambda_{r}\right) w^{\mathrm{MS} *}+\alpha x^{\mathrm{MS} *}}{2 b+\sigma^{2} \lambda_{r}} .
$$

\section{B. Proof of Proposition 2}

Part (1): by taking the first-order conditions of $w^{\mathrm{MS} *}, x^{\mathrm{MS} *}$, and $p^{\mathrm{MS} *}$ with respect to $\lambda_{m}$, respectively, we get

$$
\begin{aligned}
& \frac{\partial w^{\mathrm{MS} *}}{\partial \lambda_{m}} \\
& =-r^{2} \sigma^{2}\left(b+\lambda_{r} \sigma^{2}\right)\left(2 b+\lambda_{r} \sigma^{2}\right)^{3}(a-b c) \\
& \times\left[2 b \lambda_{r} \sigma^{2}\left(3 r b-\alpha^{2}\right)+b^{2}\left(4 r b-\alpha^{2}\right)\right. \\
& \left.+\lambda_{r}^{2} \sigma^{4}\left(2 r b-\alpha^{2}\right)+r \sigma^{2} \lambda_{m}\left(2 b+\lambda_{r} \sigma^{2}\right)^{2}\right]^{-2}, \\
& \frac{\partial x^{\mathrm{MS} *}}{\partial \lambda_{m}} \\
& =-\alpha r \sigma^{2}\left(2 b+\lambda_{r} \sigma^{2}\right)^{2}\left(b+\lambda_{r} \sigma^{2}\right)^{2}(a-b c) \\
& \times\left[2 b \lambda_{r} \sigma^{2}\left(3 r b-\alpha^{2}\right)+b^{2}\left(4 r b-\alpha^{2}\right)\right. \\
& \left.+\lambda_{r}^{2} \sigma^{4}\left(2 r b-\alpha^{2}\right)+r \sigma^{2} \lambda_{m}\left(2 b+\lambda_{r} \sigma^{2}\right)^{2}\right]^{-2}, \\
& \frac{\partial p^{\mathrm{MS} *}}{\partial \lambda_{m}} \\
& =-r \sigma^{2}\left(b+\lambda_{r} \sigma^{2}\right)^{2}\left(2 b+\lambda_{r} \sigma^{2}\right)^{3}\left[\alpha^{2}+r\left(2 b+\lambda_{r} \sigma^{2}\right)\right] \\
& \times(a-b c)\left(\left(2 b+\sigma^{2} \lambda_{r}\right)^{2}\right.
\end{aligned}
$$

$$
\begin{gathered}
\times\left[2 b \lambda_{r} \sigma^{2}\left(3 r b-\alpha^{2}\right)+b^{2}\left(4 r b-\alpha^{2}\right)\right. \\
+\lambda_{r}^{2} \sigma^{4}\left(2 r b-\alpha^{2}\right) \\
\left.\left.+r \sigma^{2} \lambda_{m}\left(2 b+\lambda_{r} \sigma^{2}\right)^{2}\right]^{2}\right)^{-1} .
\end{gathered}
$$

We have $a-b c>0$, so $\partial w^{\mathrm{MS} *} / \partial \lambda_{m}<0, \partial x^{\mathrm{MS} *} / \partial \lambda_{m}<0$, and $\partial p^{\mathrm{MS} *} / \partial \lambda_{m}<0$.

Part (2): by taking the first-order conditions of $w^{\mathrm{MS} *}$, $x^{\mathrm{MS} *}$, and $p^{\mathrm{MS} *}$ with respect to $\lambda_{r}$, respectively, we get

$$
\begin{aligned}
& \frac{\partial w^{\mathrm{MS} *}}{\partial \lambda_{r}} \\
& =b r \sigma^{2}\left[\alpha^{2}\left(b+\lambda_{r} \sigma^{2}\right)^{2}+\lambda_{m} r \sigma^{2}\left(2 b+\lambda_{r} \sigma^{2}\right)^{2}\right] \\
& \quad \times(a-b c)\left[2 b \lambda_{r} \sigma^{2}\left(3 r b-\alpha^{2}\right)\right. \\
& +b^{2}\left(4 r b-\alpha^{2}\right)+\lambda_{r}^{2} \sigma^{4}\left(2 r b-\alpha^{2}\right) \\
& \left.+r \sigma^{2} \lambda_{m}\left(2 b+\lambda_{r} \sigma^{2}\right)^{2}\right]^{-2},
\end{aligned}
$$

$\frac{\partial x^{\mathrm{MS} *}}{\partial \lambda_{r}}$

$$
\begin{gathered}
=2 b \alpha r \sigma^{2}\left(b+\lambda_{r} \sigma^{2}\right)\left[b\left(b+\lambda_{r} \sigma^{2}\right)+\lambda_{m} \sigma^{2}\left(2 b+\lambda_{r} \sigma^{2}\right)\right] \\
\times(a-b c)\left[2 b \lambda_{r} \sigma^{2}\left(3 r b-\alpha^{2}\right)\right. \\
+b^{2}\left(4 r b-\alpha^{2}\right)+\lambda_{r}^{2} \sigma^{4}\left(2 r b-\alpha^{2}\right) \\
\left.+r \sigma^{2} \lambda_{m}\left(2 b+\lambda_{r} \sigma^{2}\right)^{2}\right]^{-2}
\end{gathered}
$$

$\frac{\partial p^{\mathrm{MS} *}}{\partial \lambda_{r}}$

$=\left\{-r \sigma^{2}\left(2 b+\lambda_{r} \sigma^{2}\right)^{2}\right.$

$\times\left\{2 b\left(b r-\alpha^{2}\right)\left(b+\lambda_{r} \sigma^{2}\right)^{2}\right.$

$$
+r \lambda_{m}^{2} \sigma^{4}\left(2 b+\lambda_{r} \sigma^{2}\right)^{2}+b^{2} \lambda_{m} \sigma^{2}\left(4 b r-3 \alpha^{2}\right)
$$$$
\left.+2 b \lambda_{m} \lambda_{r} \sigma^{4}\left(3 b r-2 \alpha^{2}\right)+\lambda_{m} \lambda_{r}^{2} \sigma^{6}\left(2 b r-\alpha^{2}\right)\right\}
$$$$
\times(a-b c)\} \times\left\{\left(2 b+\sigma^{2} \lambda_{r}\right)^{2}\right.
$$

$$
\begin{aligned}
& \times\left[2 b \lambda_{r} \sigma^{2}\left(3 r b-\alpha^{2}\right)\right. \\
& +b^{2}\left(4 r b-\alpha^{2}\right)+\lambda_{r}^{2} \sigma^{4}\left(2 r b-\alpha^{2}\right) \\
& \left.\left.\quad+r \sigma^{2} \lambda_{m}\left(2 b+\lambda_{r} \sigma^{2}\right)^{2}\right]^{2}\right\}^{-1} .
\end{aligned}
$$


We have $a-b c>0$, so $\partial x^{\mathrm{MS} *} / \partial \lambda_{m}>0$ and $\partial w^{\mathrm{MS} *} / \partial \lambda_{m}>0$. When $\lambda_{m}=0$ and $\lambda_{r}=0$, the manufacturer and the retailer are all risk-neutral decision makers. Their wholesale price is $w_{0}=\left(2 r(a+b c)-c \alpha^{2}\right) /\left(4 r b-\alpha^{2}\right)$ and the retail price is $p_{0}=$ $\left(r(3 a+b c)-c \alpha^{2}\right) /\left(4 r b-\alpha^{2}\right)$. As $p_{0}-w_{0}=r(a-b c) /\left(4 r b-\alpha^{2}\right)>$ 0 and $a-b c>0$, there is $4 r b-\alpha^{2}>0$. With all other conditions being equal, the increase of production cost results in a rise in prices. So $\partial w_{0} / \partial c=\left(2 r b-\alpha^{2}\right) /\left(4 r b-\alpha^{2}\right)>0, \partial p_{0} / \partial c=$ $\left(r b-\alpha^{2}\right) /\left(4 r b-\alpha^{2}\right)>0$. Therefore, we have $r b-\alpha^{2}>0$ and $\partial p^{\mathrm{MS} *} / \partial \lambda_{m}<0$. The condition $r b-\alpha^{2}>0$ assures that the utility function is concave in the quality improvement, which means that it not be too cheap to improve quality.

\section{Proof of Proposition 3}

By taking the first-order conditions of $w^{\mathrm{MS} *}, x^{\mathrm{MS} *}$, and $p^{\mathrm{MS} *}$ with respect to $r$, respectively, we get

$$
\begin{aligned}
& \frac{\partial w^{\mathrm{MS} *}}{\partial r}=-\alpha^{2}\left(2 b+\lambda_{r} \sigma^{2}\right)\left(b+\lambda_{r} \sigma^{2}\right)^{3}(a-b c) \\
& \times\left[2 b \lambda_{r} \sigma^{2}\left(3 r b-\alpha^{2}\right)+b^{2}\left(4 r b-\alpha^{2}\right)\right. \\
& \left.+\lambda_{r}^{2} \sigma^{4}\left(2 r b-\alpha^{2}\right)+r \sigma^{2} \lambda_{m}\left(2 b+\lambda_{r} \sigma^{2}\right)^{2}\right]^{-2} \\
& \frac{\partial x^{\mathrm{MS} *}}{\partial r}=-\alpha\left(2 b+\lambda_{r} \sigma^{2}\right)\left(b+\lambda_{r} \sigma^{2}\right)^{2} \\
& \times\left[2 b\left(b+\lambda_{m} \sigma^{2}\right)+\lambda_{r} \sigma^{2}\left(2 b+\lambda_{m} \sigma^{2}\right)\right](a-b c) \\
& \times\left[2 b \lambda_{r} \sigma^{2}\left(3 r b-\alpha^{2}\right)+b^{2}\left(4 r b-\alpha^{2}\right)\right. \\
& \left.+\lambda_{r}^{2} \sigma^{4}\left(2 r b-\alpha^{2}\right)+r \sigma^{2} \lambda_{m}\left(2 b+\lambda_{r} \sigma^{2}\right)^{2}\right]^{-2}, \\
& \frac{\partial p^{\mathrm{MS} *}}{\partial r}=-\alpha^{2}\left(2 b+\lambda_{r} \sigma^{2}\right)^{2}\left(b+\lambda_{r} \sigma^{2}\right)^{2} \\
& \times\left[b\left(3 b+2 \lambda_{r} \sigma^{2}\right)+\sigma^{2}\left(2 b+\lambda_{r} \sigma^{2}\right)\left(\lambda_{m}+\lambda_{r}\right)\right] \\
& \times(a-b c)\left(\left(2 b+\sigma^{2} \lambda_{r}\right)^{2}\right. \\
& \times\left[2 b \lambda_{r} \sigma^{2}\left(3 r b-\alpha^{2}\right)+b^{2}\left(4 r b-\alpha^{2}\right)\right. \\
& +\lambda_{r}^{2} \sigma^{4}\left(2 r b-\alpha^{2}\right) \\
& \left.\left.+r \sigma^{2} \lambda_{m}\left(2 b+\lambda_{r} \sigma^{2}\right)^{2}\right]^{2}\right)^{-1}
\end{aligned}
$$

From $a-b c>0$, we have $\partial x^{\mathrm{MS} *} / \partial r<0, \partial w^{\mathrm{MS} *} / \partial r<0$, and $\partial p^{\mathrm{MS} *} / \partial r<0$.

\section{Proof of Proposition 4}

Hessian matrix of $U_{m}\left(\Pi_{m}\right)$ is

$$
H_{2}=\left[\begin{array}{cc}
-2 b-\lambda_{m} \sigma^{2} & \alpha \\
\alpha & -r
\end{array}\right] \text {. }
$$

The utility function $U_{m}\left(\Pi_{m}\right)$ is a concave function on $(w, x)$ if and only if Hessian matrix is negatively definited. Define $\widehat{r}_{2}=\alpha^{2} /\left(2 b+\lambda_{m} \sigma^{2}\right)$.

The first-order condition of $U_{m}\left(\Pi_{m}\right)$ can be shown as

$$
\begin{gathered}
\frac{\partial U_{m}\left(\Pi_{m}\right)}{\partial w}=a-b(w+m)+\alpha x+(w-c) \cdot(-b) \\
-\lambda_{m}(w-c) \sigma^{2}=0 \\
\frac{\partial U_{m}\left(\Pi_{m}\right)}{\partial x}=(w-c) \alpha-r x=0
\end{gathered}
$$

From solving (D.2), we obtain the optimal wholesale price and quality if $r>\widehat{r}_{2}$

$$
\begin{gathered}
w^{*}=\frac{c\left(b r-\alpha^{2}\right)+r(a-b m)+c \lambda_{m} \sigma^{2} r}{-\alpha^{2}+2 b r+\lambda_{m} \sigma^{2} r}, \\
x^{*}=\frac{\alpha(a-b m-b c)}{-\alpha^{2}+2 b r+\lambda_{m} \sigma^{2} r} .
\end{gathered}
$$

Inserting $w^{*}$ in (D.3) and $x^{*}$ in (D.4) into the utilities of the retailer, we obtain

$$
U_{r}\left(\Pi_{r}\right)=m\left[a-b\left(w^{*}+m\right)+\alpha x^{*}\right]-\frac{\lambda_{r}}{2} m^{2} \sigma^{2} .
$$

To find the optimal price, we first look at the first-order condition.

$$
\begin{aligned}
\frac{\partial U_{r}\left(\Pi_{r}\right)}{\partial m}= & a-b\left[\frac{c\left(b r-\alpha^{2}\right)+r(a-b m)+c \lambda_{m} \sigma^{2} r}{-\alpha^{2}+2 b r+\lambda_{m} \sigma^{2} r}+m\right] \\
& +\frac{\alpha^{2}(a-b m-b c)}{-\alpha^{2}+2 b r+\lambda_{m} \sigma^{2} r} \\
& +m\left[-b\left(\frac{-b r}{-\alpha^{2}+2 b r+\lambda_{m} \sigma^{2} r}+1\right)\right. \\
& \left.-\frac{b \alpha^{2}}{-\alpha^{2}+2 b r+\lambda_{m} \sigma^{2} r}\right]-\lambda_{r} m \sigma^{2}
\end{aligned}
$$

The second-order condition is $\partial^{2} U_{r}\left(\Pi_{r}\right) / \partial m^{2}<0$. Therefore, the utility function $U_{r}\left(\Pi_{r}\right)$ is strictly concave in price markup.

Solving $\partial U_{r}\left(\Pi_{r}\right) / \partial m=0$, we derive the retailer's optimal price markup

$$
m^{\mathrm{RS} *}=\frac{r(a-b c)\left(b+\lambda_{m} \sigma^{2}\right)}{2 b r\left(b+\lambda_{m} \sigma^{2}\right)+\sigma^{2} \lambda_{r}\left(2 b r-\alpha^{2}\right)+\lambda_{m} \lambda_{r} \sigma^{4} r} .
$$


Therefore, the optimal wholesale price and quality are

$$
\begin{gathered}
w^{\mathrm{RS} *}=\frac{c\left(b r-\alpha^{2}\right)+r\left(a-b m^{\mathrm{RS} *}\right)+c \lambda_{m} \sigma^{2} r}{-\alpha^{2}+2 b r+\lambda_{m} \sigma^{2} r}, \\
x^{\mathrm{RS} *}=\frac{\alpha\left(a-b m^{\mathrm{RS} *}-b c\right)}{-\alpha^{2}+2 b r+\lambda_{m} \sigma^{2} r}
\end{gathered}
$$

and the optimal retail price is

$$
p^{\mathrm{RS} *}=w^{\mathrm{RS} *}+m^{\mathrm{RS} *} .
$$

\section{E. Proof of Proposition 5}

Part (1): we solve the first-order conditions of $w^{\mathrm{RS} *}, x^{\mathrm{RS} *}$, and $p^{\mathrm{RS} *}$ with respect to $\lambda_{m}$, respectively; we get

$$
\begin{aligned}
& \frac{\partial w^{\mathrm{RS} *}}{\partial \lambda_{m}} \\
& =\left\{-r^{2} \sigma^{2}(a-b c)\right. \\
& \times\left\{2 b^{2} r^{2}\left(b+\lambda_{m} \sigma^{2}\right)^{2}+2 b \lambda_{r} r \sigma^{2}\right. \\
& \times\left[b\left(4 b r-3 \alpha^{2}\right)+2 \lambda_{r} \sigma^{2}\left(b r-\alpha^{2}\right)\right] \\
& +2 \lambda_{m} \lambda_{r} r \sigma^{4}\left[b\left(5 b r-2 \alpha^{2}\right)+\lambda_{r} \sigma^{2}\left(2 b r-\alpha^{2}\right)\right] \\
& +\lambda_{m}^{2} \lambda_{r} r^{2} \sigma^{6}\left(3 b+\lambda_{r} \sigma^{2}\right) \\
& \left.\left.+\lambda_{r} \alpha^{4} \sigma^{2}\left(b+\lambda_{r} \sigma^{2}\right)\right\}\right\} \\
& \times\left\{\left(-\alpha^{2}+2 b r+\lambda_{m} \sigma^{2} r\right)\right. \\
& \times\left[2 b r\left(b+\lambda_{m} \sigma^{2}\right)+\sigma^{2} \lambda_{r}\left(2 b r-\alpha^{2}\right)\right. \\
& \left.\left.+\lambda_{m} \lambda_{r} \sigma^{4} r\right]\right\}^{-2} \\
& \frac{\partial x^{\mathrm{RS} *}}{\partial \lambda_{m}}=\left\{-\alpha r \sigma^{2}\right. \\
& \times\left\{2 b^{2} r^{2}\left(b+\lambda_{m} \sigma^{2}\right)^{2}+2 b \lambda_{s} r \sigma^{2}\right. \\
& \times\left[b\left(4 b r-3 \alpha^{2}\right)+2 \lambda_{s} \sigma^{2}\left(b r-\alpha^{2}\right)\right] \\
& +2 \lambda_{m} \lambda_{s} r \sigma^{4}\left[b\left(5 b r-2 \alpha^{2}\right)+\lambda_{s} \sigma^{2}\left(2 b r-\alpha^{2}\right)\right] \\
& \left.+\lambda_{m}^{2} \lambda_{s} r^{2} \sigma^{6}\left(3 b+\lambda_{s} \sigma^{2}\right)+\lambda_{s} \alpha^{4} \sigma^{2}\left(b+\lambda_{s} \sigma^{2}\right)\right\} \\
& \times(a-b c)\} \\
& \times\left\{\left(-\alpha^{2}+2 b r+\lambda_{m} \sigma^{2} r\right)\right. \\
& \times\left[2 b r\left(b+\lambda_{m} \sigma^{2}\right)+\sigma^{2} \lambda_{r}\left(2 b r-\alpha^{2}\right)\right. \\
& \left.\left.+\lambda_{m} \lambda_{r} \sigma^{4} r\right]\right\}^{-2}
\end{aligned}
$$

$$
\begin{aligned}
& \frac{\partial p^{\mathrm{RS} *}}{\partial \lambda_{m}} \\
& =\left\{-r \sigma^{2}(a-b c)\right. \\
& \times\left\{2 b^{2} r^{3}\left(b+\lambda_{m} \sigma^{2}\right)^{2}+2 b \lambda_{r} r \sigma^{2}\right. \\
& \times\left[\lambda_{m} r^{2} \sigma^{2}\left(3 b+\lambda_{m} \sigma^{2}\right)+\left(2 b^{2} r^{2}-\alpha^{4}\right)\right] \\
& +2 \lambda_{r}^{2} r^{2} \sigma^{4}\left[2 b\left(b r-\alpha^{2}\right)+\lambda_{m} \sigma^{2}\left(2 b r-\alpha^{2}\right)\right] \\
& +2 \lambda_{r} \alpha^{2} r \sigma^{2}\left(b+\lambda_{m} \sigma^{2}\right)\left(b r-\alpha^{2}\right) \\
& \left.\left.+\lambda_{r} \sigma^{2}\left(\lambda_{r} r \sigma^{2}+\alpha^{2}\right)\left(\lambda_{m}^{2} r^{2} \sigma^{4}+\alpha^{4}\right)\right\}\right\} \\
& \times\left\{\left(-\alpha^{2}+2 b r+\lambda_{m} \sigma^{2} r\right)\right. \\
& \times\left[2 b r\left(b+\lambda_{m} \sigma^{2}\right)+\sigma^{2} \lambda_{r}\left(2 b r-\alpha^{2}\right)\right. \\
& \left.\left.+\lambda_{m} \lambda_{r} \sigma^{4} r\right]\right\}^{-2} \text {. }
\end{aligned}
$$

From $a-b c>0$ and $r b-\alpha^{2}>0$, we have $\partial w^{\mathrm{RS} *} / \partial \lambda_{m}<0$, $\partial x^{\mathrm{RS} *} / \partial \lambda_{m}<0$, and $\partial p^{\mathrm{RS*}} / \partial \lambda_{m}<0$.

Part (2): we solve the first-order conditions of $m, w^{\mathrm{RS} *}$, $x^{\mathrm{RS} *}$, and $p^{\mathrm{RS} *}$ with respect to $\lambda_{r}$, respectively; we get

$$
\begin{gathered}
\frac{\partial m}{\partial \lambda_{r}}=\frac{-r \sigma^{2}\left(b+\lambda_{m} \sigma^{2}\right)\left[r\left(2 b+\lambda_{m} \sigma^{2}\right)-\alpha^{2}\right](a-b c)}{\left[2 b r\left(b+\lambda_{m} \sigma^{2}\right)+\sigma^{2} \lambda_{r}\left(2 b r-\alpha^{2}\right)+\lambda_{m} \lambda_{r} \sigma^{4} r\right]^{2}}, \\
\frac{\partial w^{\mathrm{RS} *}}{\partial \lambda_{r}}=\frac{-b r}{\left(-\alpha^{2}+2 b r+\lambda_{m} \sigma^{2} r\right)} \cdot \frac{\partial m}{\partial \lambda_{r}}, \\
\frac{\partial x^{\mathrm{RS} *}}{\partial \lambda_{r}}=\frac{-b \alpha}{\left(-\alpha^{2}+2 b r+\lambda_{m} \sigma^{2} r\right)} \cdot \frac{\partial m}{\partial \lambda_{r}},
\end{gathered}
$$$$
\frac{\partial p^{\mathrm{RS} *}}{\partial \lambda_{r}}=-r \sigma^{2}\left(b+\lambda_{m} \sigma^{2}\right)\left[r\left(b+\lambda_{m} \sigma^{2}\right)-\alpha^{2}\right]
$$$$
\times\left[r\left(2 b+\lambda_{m} \sigma^{2}\right)-\alpha^{2}\right]^{2}(a-b c)
$$$$
\times\left\{\left(-\alpha^{2}+2 b r+\lambda_{m} \sigma^{2} r\right)\right.
$$$$
\times\left[2 b r\left(b+\lambda_{m} \sigma^{2}\right)+\sigma^{2} \lambda_{r}\left(2 b r-\alpha^{2}\right)\right.
$$$$
\left.\left.+\lambda_{m} \lambda_{r} \sigma^{4} r\right]\right\}^{-2}
$$

From $a-b c>0$ and $r b-\alpha^{2}>0$, we have $\partial m^{\mathrm{RS} *} / \partial \lambda_{r}<0$, $\partial w^{\mathrm{RS} *} / \partial \lambda_{r}>0, \partial x^{\mathrm{RS} *} / \partial \lambda_{r}>0$, and $\partial p^{\mathrm{RS} *} / \partial \lambda_{r}<0$. 


\section{F. Proof of Proposition 6}

We solve the first-order conditions of $w^{\mathrm{RS} *}, x^{\mathrm{RS} *}$, and $p^{\mathrm{RS} *}$ with respect to $r$, respectively; we get

$$
\begin{aligned}
& \frac{\partial w^{\mathrm{RS} *}}{\partial r} \\
& =\left\{-\alpha^{2}(a-b c)\right. \\
& \times\left\{2 b^{2} r^{2}\left(b+\lambda_{m} \sigma^{2}\right)^{2}+2 b \lambda_{r} r \sigma^{2}\right. \\
& \times\left[b\left(2 b r-\alpha^{2}\right)+2 \lambda_{r} \sigma^{2}\left(b r-\alpha^{2}\right)\right] \\
& +2 \lambda_{m} \lambda_{r} r \sigma^{4}\left[b\left(3 b r-\alpha^{2}\right)+\lambda_{r} \sigma^{2}\left(2 b r-\alpha^{2}\right)\right] \\
& \left.\left.+\lambda_{r} \sigma^{4}\left[\lambda_{m}^{2} r^{2} \sigma^{2}\left(2 b+\lambda_{r} \sigma^{2}\right)+\lambda_{r} \sigma^{4}\right]\right\}\right\} \\
& \times\left\{\left(-\alpha^{2}+2 b r+\lambda_{m} \sigma^{2} r\right)\right. \\
& \left.\times\left[2 b r\left(b+\lambda_{m} \sigma^{2}\right)+\sigma^{2} \lambda_{r}\left(2 b r-\alpha^{2}\right)+\lambda_{m} \lambda_{r} \sigma^{4} r\right]\right\}^{-2}, \\
& \frac{\partial x^{\mathrm{RS} *}}{\partial r} \\
& =\{-\alpha(a-b c) \\
& \times\left\{2 b^{4} r^{2}\left(2 b+5 \lambda_{m} \sigma^{2}\right)+\lambda_{m}^{2} r^{2} \sigma^{4}\right. \\
& \times\left[2 b^{2}\left(4 b+\lambda_{m} \sigma^{2}\right)+\lambda_{m} \lambda_{r} \sigma^{4}\left(3 b+\lambda_{r} \sigma^{2}\right)\right] \\
& +4 b^{2} \lambda_{r} r \sigma^{2}\left[b\left(3 b r-2 \alpha^{2}\right)\right. \\
& \left.+2 \lambda_{r} \sigma^{2}\left(b r-\alpha^{2}\right)\right]+b \lambda_{m} \lambda_{r} r \sigma^{4} \\
& \times\left[12 b\left(2 b r-\alpha^{2}\right)+\lambda_{m} \sigma^{2}\left(15 b r-4 \alpha^{2}\right)\right] \\
& +2 \lambda_{m} \lambda_{r}^{2} r \sigma^{6}\left[2 b\left(3 b r-2 \alpha^{2}\right)\right. \\
& \left.+\lambda_{m} \sigma^{2}\left(3 b r-\alpha^{2}\right)\right]+\lambda_{r} \alpha^{4} \sigma^{2} \\
& \left.\left.\times\left[b\left(b+\lambda_{m} \sigma^{2}\right)+\lambda_{r} \sigma^{2}\left(2 b+\lambda_{m} \sigma^{2}\right)\right]\right\}\right\} \\
& \times\left\{\left(-\alpha^{2}+2 b r+\lambda_{m} \sigma^{2} r\right)\right. \\
& \times\left[2 b r\left(b+\lambda_{m} \sigma^{2}\right)+\sigma^{2} \lambda_{r}\left(2 b r-\alpha^{2}\right)\right. \\
& \left.\left.+\lambda_{m} \lambda_{r} \sigma^{4} r\right]\right\}^{-2}, \\
& \frac{\partial p^{\mathrm{RS} *}}{\partial r} \\
& =\left\{-\alpha^{2}(a-b c)\right. \\
& \times\left\{2 b^{2} r^{2}\left(b+\lambda_{m} \sigma^{2}\right)^{2}+2 b \lambda_{r} r \sigma^{2}\right. \\
& \times\left[b\left(4 b r-3 \alpha^{2}\right)+2 \lambda_{r} \sigma^{2}\left(b r-\alpha^{2}\right)\right]
\end{aligned}
$$

$$
\begin{gathered}
+\lambda_{m} \lambda_{r} r \sigma^{4}\left[2 b\left(7 b r-4 \alpha^{2}\right)\right. \\
\left.+\lambda_{m} \sigma^{2}\left(7 b r-2 \alpha^{2}\right)\right] \\
+2 \lambda_{m} \lambda_{r}^{2} r \sigma^{6}\left(2 b r-\alpha^{2}\right)+\lambda_{r} \alpha^{4} \sigma^{2} \\
\left.\left.\times\left(b+\lambda_{m} \sigma^{2}+\lambda_{r} \sigma^{2}\right)+\lambda_{m}^{2} \lambda_{r} r^{2} \sigma^{8}\left(\lambda_{m}+\lambda_{r}\right)\right\}\right\} \\
\times\left\{\left(-\alpha^{2}+2 b r+\lambda_{m} \sigma^{2} r\right)\right. \\
\times\left[2 b r\left(b+\lambda_{m} \sigma^{2}\right)\right. \\
\left.\left.+\sigma^{2} \lambda_{r}\left(2 b r-\alpha^{2}\right)+\lambda_{m} \lambda_{r} \sigma^{4} r\right]\right\}^{-2} .
\end{gathered}
$$

From $a-b c>0$ and $r b-\alpha^{2}>0$, we have $\partial x^{\mathrm{RS} *} / \partial r<0$, $\partial w^{\mathrm{RS} *} / \partial r<0$, and $\partial p^{\mathrm{RS} *} / \partial r<0$

\section{Conflict of Interests}

The authors declare that there is no conflict of interests regarding the publication of this paper.

\section{Acknowledgments}

The authors sincerely thank the editor and the anonymous reviewers for their valuable comments and suggestions, which have enormously improved this paper. This paper is partially supported by (1) the Fund for Humanity and Social Science of the Ministry of Education of China (Research on multiagent collaborative innovation management mechanism under open innovation environment) and (2) the National Natural Science Foundation of China (71172213).

\section{References}

[1] J. Wu, S. Wang, X. Chao, C. T. Ng, and T. C. E. Cheng, "Impact of risk aversion on optimal decisions in supply contracts," International Journal of Production Economics, vol. 128, no. 2, pp. 569-576, 2010.

[2] K. Matsui, "Returns policy, new model introduction, and consumer welfare," International Journal of Production Economics, vol. 124, no. 2, pp. 299-309, 2010.

[3] T. Xiao and D. Yang, "Risk sharing and information revelation mechanism of a one-manufacturer and one-retailer supply chain facing an integrated competitor," European Journal of Operational Research, vol. 196, no. 3, pp. 1076-1085, 2009.

[4] T. Xiao and D. Yang, "Price and service competition of supply chains with risk-averse retailers under demand uncertainty," International Journal of Production Economics, vol. 114, no. 1, pp. 187-200, 2008.

[5] O. Flaten and G. Lien, "Stochastic utility-efficient programming of organic dairy farms," European Journal of Operational Research, vol. 181, no. 3, pp. 1574-1583, 2007.

[6] J. A. Gómez-Limón, M. Arriaza, and L. Riesgo, "An MCDM analysis of agricultural risk aversion," European Journal of Operational Research, vol. 151, no. 3, pp. 569-585, 2003. 
[7] A. J. Dalal and M. Alghalith, "Production decisions under joint price and production uncertainty," European Journal of Operational Research, vol. 197, no. 1, pp. 84-92, 2009.

[8] R. D. Banker, I. Khosla, and K. K. Sinha, "Quality and competition," Management Science, vol. 44, no. 9, pp. 1179-1192, 1998.

[9] N. Matsubayashi, "Price and quality competition: the effect of differentiation and vertical integration," European Journal of Operational Research, vol. 180, no. 2, pp. 907-921, 2007.

[10] H. Gurnani and M. Erkoc, "Supply contracts in manufacturerretailer interactions with manufacturer-quality and retailer effort-induced demand," Naval Research Logistics, vol. 55, no. 3, pp. 200-217, 2008.

[11] X. Xu, "Optimal price and product quality decisions in a distribution channel," Management Science, vol. 55, no. 8, pp. 1347-1352, 2009.

[12] F. El Ouardighi and B. Kim, "Supply quality management with wholesale price and revenue-sharing contracts under horizontal competition," European Journal of Operational Research, vol. 206, no. 2, pp. 329-340, 2010.

[13] G. Xie, W. Yue, S. Wang, and K. K. Lai, "Quality investment and price decision in a risk-averse supply chain," European Journal of Operational Research, vol. 214, no. 2, pp. 403-410, 2011.

[14] D. Wu, "Joint pricing-servicing decision and channel strategies in the supply chain," Central European Journal of Operations Research, vol. 19, no. 1, pp. 99-137, 2011.

[15] N. C. Petruzzi and M. Dada, "Pricing and the newsvendor problem: a review with extensions," Operations Research, vol. 47, no. 2, pp. 183-194, 1999.

[16] L. M. Chan, Z. M. Shen, D. Simchi-Levi, and J. L. Swann, "Coordination of pricing and inventory decisions: a survey and classification," in Handbook of Quantitative Supply Chain Analysis, pp. 335-392, Springer, 2004.

[17] F. J. Arcelus and G. Srinivasan, "Inventory policies under various optimizing criteria and variable markup rates," Management Science, vol. 33, no. 6, pp. 756-762, 1987.

[18] H. Gurnani, M. Erkoc, and Y. Luo, "Impact of product pricing and timing of investment decisions on supply chain coopetition," European Journal of Operational Research, vol. 180, no. 1, pp. 228-248, 2007.

[19] T.-M. Choi, D. Li, H. Yan, and C.-H. Chiu, "Channel coordination in supply chains with agents having mean-variance objectives," Omega, vol. 36, no. 4, pp. 565-576, 2008.

[20] A. A. Tsay, "Risk sensitivity in distribution channel partnerships: Implications for manufacturer return policies," Journal of Retailing, vol. 78, no. 2, pp. 147-160, 2002.

[21] X. Gan, S. P. Sethi, and H. Yan, "Channel coordination with a risk-neutral supplier and a downside-risk-averse retailer," Production and Operations Management, vol. 14, no. 1, pp. 8089, 2005.

[22] F. J. Arcelus, S. Kumar, and G. Srinivasan, "Risk tolerance and a retailer's pricing and ordering policies within a newsvendor framework," Omega, vol. 40, no. 2, pp. 188-198, 2012.

[23] B. Li, Y. Zhou, and B. Niu, "Contract strategies in competing supply chains with risk-averse suppliers," Mathematical Problems in Engineering, vol. 2013, Article ID 938124, 12 pages, 2013.

[24] M. Xu, Q. Wang, and L. Ouyang, "Coordinating contracts for two-stage fashion supply chain with risk-averse retailer and price-dependent demand," Mathematical Problems in Engineering, vol. 2013, Article ID 259164, 2013.

[25] T. Choi, D. Li, and H. Yan, "Mean-variance analysis of a single supplier and retailer supply chain under a returns policy,"
European Journal of Operational Research, vol. 184, no. 1, pp. 356-376, 2008.

[26] T. Xiao and T.-M. Choi, "Purchasing choices and channel structure strategies for a two-echelon system with risk-averse players," International Journal of Production Economics, vol. 120, no. 1, pp. 54-65, 2009.

[27] S. C. Choi, "Price competition in a channel structure with a common retailer," Marketing Science, vol. 10, no. 4, pp. 271-296, 1991.

[28] Y. Dong, V. Shankar, and M. Dresner, "Efficient replenishment in the distribution channel," Journal of Retailing, vol. 83, no. 3, pp. 253-278, 2007.

[29] X. T. Tang, S. J. Fang, and F. Cheng, "Strategic interactions in service supply chain with horizontal competition," TOP, pp. 120, 2012.

[30] T. Xiao, T.-M. Choi, and T. C. E. Cheng, "Product variety and channel structure strategy for a retailer-Stackelberg supply chain," European Journal of Operational Research, vol. 233, no. 1, pp. 114-124, 2014.

[31] J. Xie and J. C. Wei, "Coordinating advertising and pricing in a manufacturer-retailer channel," European Journal of Operational Research, vol. 197, no. 2, pp. 785-791, 2009.

[32] S. M. Gilbert and V. Cvsa, "Strategic commitment to price to stimulate downstream innovation in a supply chain," European Journal of Operational Research, vol. 150, no. 3, pp. 617-639, 2003.

[33] J. Veldman and G. Gaalman, "A model of strategic product quality and process improvement incentives," International Journal of Production Economics, vol. 149, pp. 202-210.

[34] E. Appelbaum and C. Lim, "Contestable markets under uncertainty," The RAND Journal of Economics, pp. 28-40, 1985.

[35] B. J. Spencer and J. A. Brander, "Pre-commitment and flexibility: applications to oligopoly theory," European Economic Review, vol. 36, no. 8, pp. 1601-1626, 1992.

[36] W. K. Chiang, D. Chhajed, and J. D. Hess, "Direct marketing, indirect profits: a strategic analysis of dual-channel supplychain design," Management Science, vol. 49, no. 1, pp. 1-20, 2003.

[37] A. A. Tsay and N. Agrawal, "Channel dynamics under price and service competition," Manufacturing and Service Operations Management, vol. 2, no. 4, pp. 372-391, 2000. 


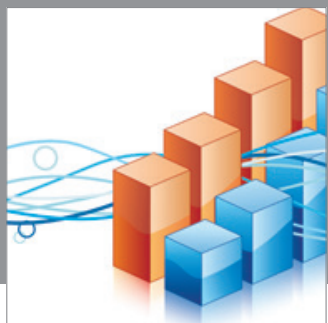

Advances in

Operations Research

mansans

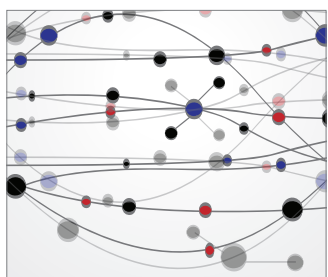

The Scientific World Journal
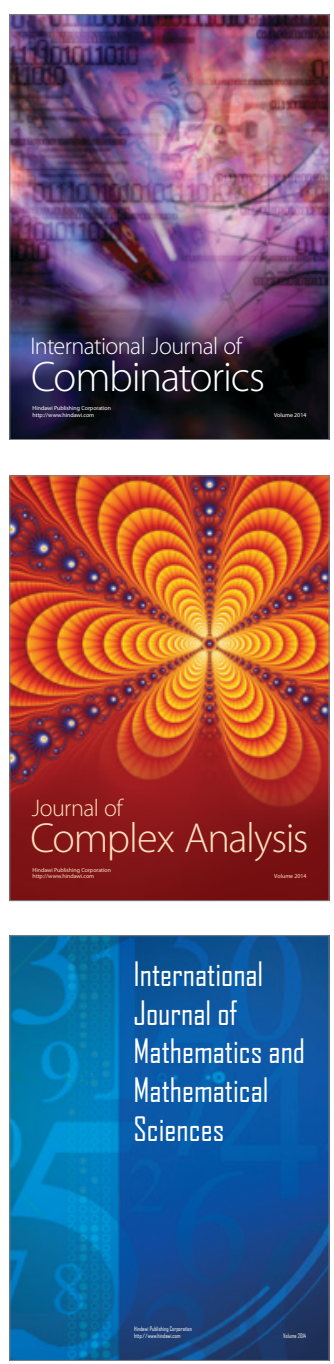
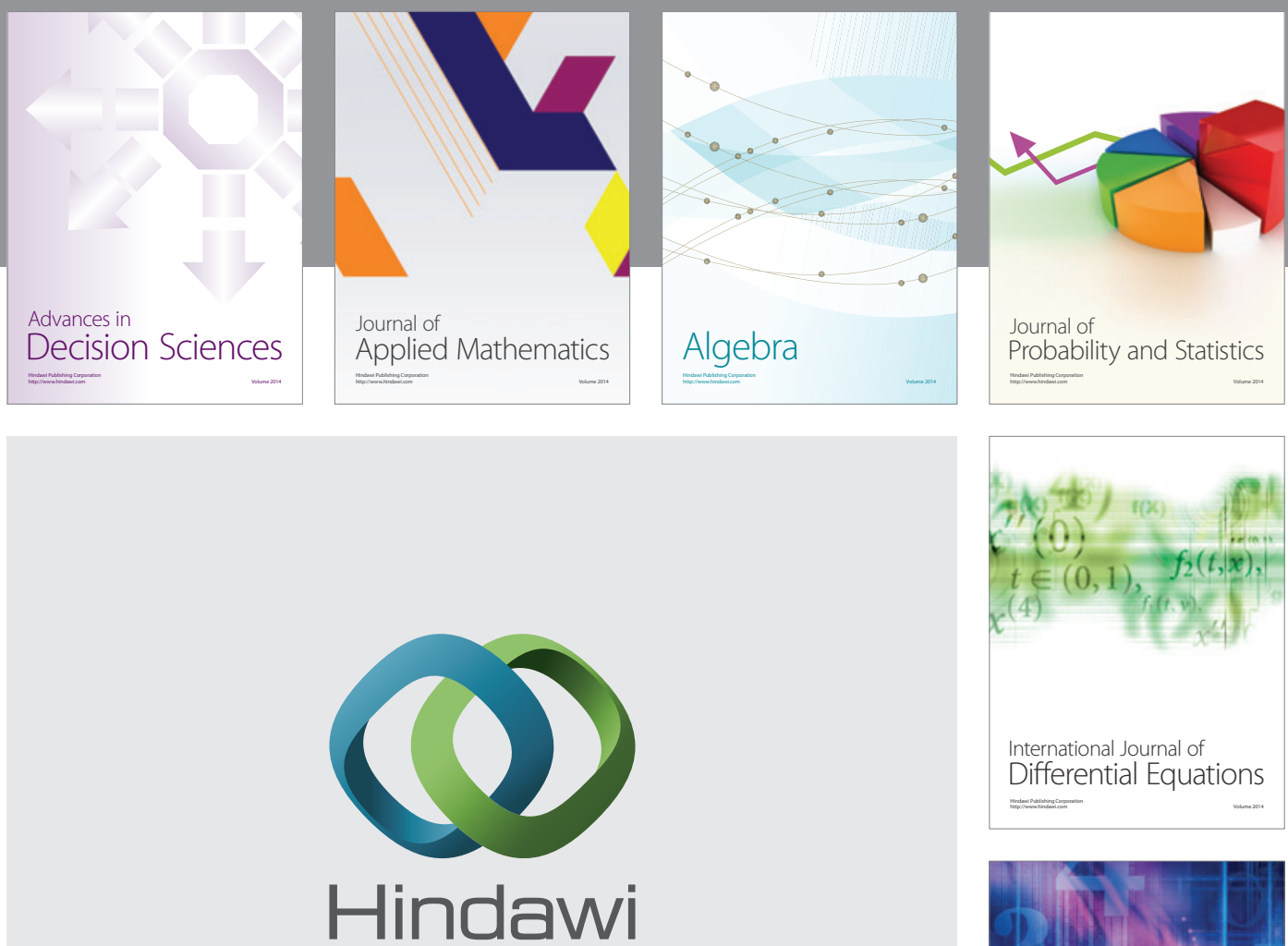

Submit your manuscripts at http://www.hindawi.com
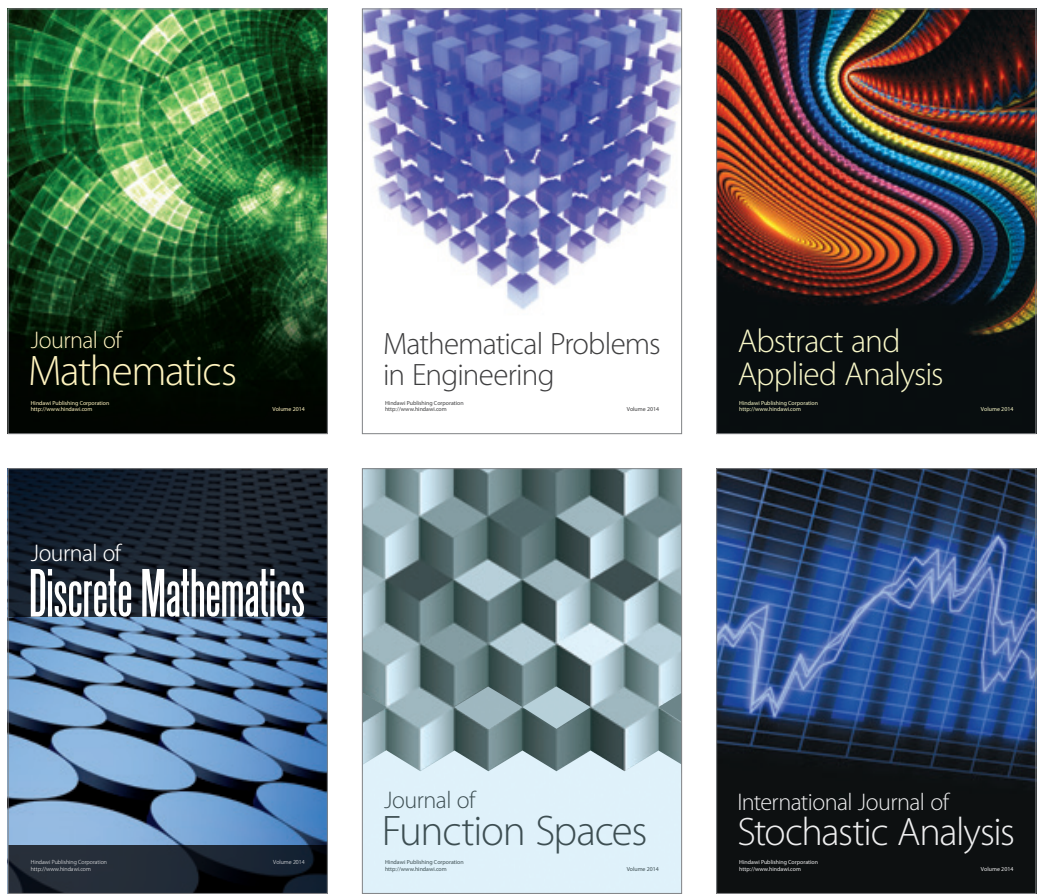

Journal of

Function Spaces

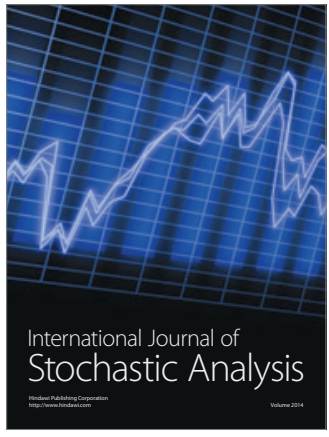

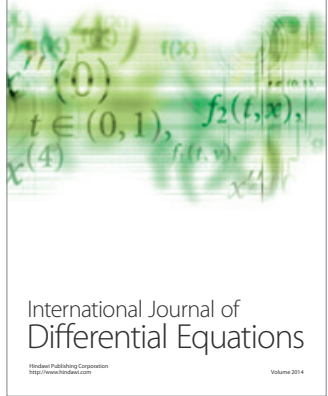
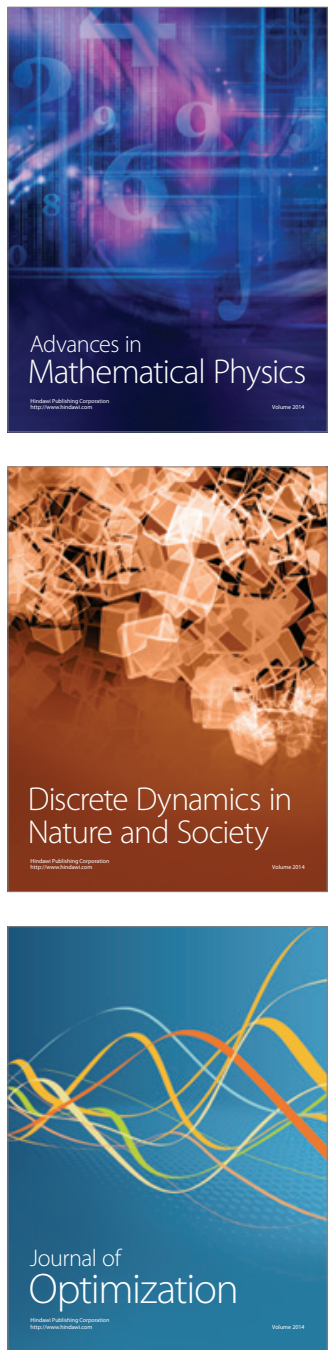